\title{
Effects of poly (ADP-ribose) polymerase-1 (PARP-1) inhibition on sulfur mustard-induced cutaneous injuries in vitro and in vivo
}

Feng Liu, Ning Jiang, Zhi-yong Xiao, Jun-ping Cheng, Yi-zhou Mei, Pan Zheng, Li Wang, Xiao-rui Zhang, Xin-bo Zhou, Wen-xia Zhou, Yong-xiang Zhang

Early studies with first-generation poly (ADP-ribose) polymerase (PARP) inhibitors have already indicated some promising therapeutic potential in sulfur mustard (SM) injury. The available novel and more potential PARP inhibitors, which are undergoing clinical trials as drugs for cancer treatment, bring it back to the centre of interest. However, the role of PARP-1 in SM-induced injury is not fully understood. In this study, we selected a high potent specific PARP inhibitor ABT-888 as example to investigate the effect of PARP inhibitor in SM injury. The results showed that in mouse ear vesicant model (MEVM) and $\mathrm{HaCaT}$ cell model, PARP inhibitor ABT-888 could reduce the cell damage induced by severe SM injury. ABT-888 significantly reduced SM induced edema and epidermal necrosis in MEVM. In HaCaT cell model, ABT-888 could reduce SM-induced NAD+ATP depletion and apoptosis/necrosis. Then, we study the mechanism of PARP-1 in SM injury by knockdown of PARP-1 in HaCaT cells. Knockdown of PARP-1 protected cell viability and downregulated the apoptosis checkpoints, including p-JNK, p-P53, Caspase 9, Caspase 8, c-PARP and Caspase 3 following SM-induced injury. Furthermore, the activation of AKT can inhibit autophagy via the regulation of mTOR. Our results showed that SM exposure could significantly inhibit the activation of Akt/mTOR pathway. Knockdown of PARP-1 reversed the SM-induced suppression of the Akt/mTOR pathway. In summary, the results of our study indicated that the protective effects of downregulation of PARP-1 in SM injury may be due to the regulation of apoptosis, necrosis, energy crisis and autophagy. However, it should be noticed that PARP inhibitor ABT-888 further enhanced the phosphorylation of H2AX (S139) after SM exposure, which indicated that we should be very careful in the application of PARP inhibitors in SM injury treatment because of the enhancement of DNA damage. 
1 Effects of poly (ADP-ribose) polymerase-1 (PARP-1) inhibition on sulfur mustard-induced

2 cutaneous injuries in vitro and in vivo

3 Feng Liu ${ }^{1}$, Ning Jiang ${ }^{1}$, Zhi-yong Xiao ${ }^{1}$, Jun-ping Cheng ${ }^{1}$, Yi-zhou Mei ${ }^{1}$, Pan Zheng ${ }^{1}$, Li Wang ${ }^{1}$,

4 Xiao-rui Zhang ${ }^{1}$, Xin-bo Zhou ${ }^{1}$, Wen-xia Zhou ${ }^{1}$, Yong-xiang Zhang ${ }^{1}$

$5 \quad{ }^{1}$ Beijing Institute of Pharmacology and Toxicology, Beijing 100850, China

7 Corresponding Author:

8 Wen-xia Zhou, Yong-xiang Zhang

9 Taiping road 27, Haidian District, Beijing 100850, China

10 Email address: pharmacare@126.com zyxbigb@126.com

11 


\section{Abstract}

Early studies with first-generation poly (ADP-ribose) polymerase (PARP) inhibitors have already indicated some promising therapeutic potential in sulfur mustard (SM) injury. The available novel and more potential PARP inhibitors, which are undergoing clinical trials as drugs for cancer treatment, bring it back to the centre of interest. However, the role of PARP-1 in SMinduced injury is not fully understood. In this study, we selected a high potent specific PARP inhibitor ABT-888 as example to investigate the effect of PARP inhibitor in SM injury. The results showed that in mouse ear vesicant model (MEVM) and HaCaT cell model, PARP inhibitor ABT- 888 could reduce the cell damage induced by severe SM injury. ABT- 888 significantly reduced SM induced edema and epidermal necrosis in MEVM. In HaCaT cell model, ABT-888 could reduce SM-induced NAD ${ }^{+} / \mathrm{ATP}$ depletion and apoptosis/necrosis. Then, we study the mechanism of PARP-1 in SM injury by knockdown of PARP-1 in HaCaT cells. Knockdown of PARP-1 protected cell viability and downregulated the apoptosis checkpoints, including p-JNK, p-P53, Caspase 9, Caspase 8, c-PARP and Caspase 3 following SM-induced injury. Furthermore, the activation of AKT can inhibit autophagy via the regulation of mTOR. Our results showed that SM exposure could significantly inhibit the activation of Akt/mTOR pathway. Knockdown of PARP-1 reversed the SM-induced suppression of the Akt/mTOR pathway. In summary, the results of our study indicated that the protective effects of downregulation of PARP-1 in SM injury may be due to the regulation of apoptosis, necrosis, energy crisis and autophagy. However, it should be noticed that PARP inhibitor ABT-888 further enhanced the phosphorylation of H2AX (S139) after SM exposure, which indicated that we should be very careful in the application of PARP inhibitors in SM injury treatment because of the enhancement of DNA damage.

\section{Introduction}

Sulfur mustard (SM), a chemical warfare vesicant agent, has been used in several military conflicts, including World Wars I and II and the Iran-Iraq War (Balali-Mood and Hefazi, 2006). After World War II, SM has also been one of the most predominant agents found in the chemical weapons abandoned in China (Hanaoka et al., 2006). Due to the potential use by terrorists against civilian populations, SM is currently considered to be a plausible global threat (Smith et al., 1995). The organs most affected by SM are the skin, eyes and respiratory tract, which are the organs that come in direct contact with the toxic liquid or vapor. Dermal exposure of SM results in severe chemical burns, affecting all layers of the skin, which produces subepidermal blisters, erythema and inflammation (Balali-Mood and Hefazi, 2005; Ghanei et al., 2010; Naraghi et al., 2005). SM is a bifunctional alkylating compound that targets DNA, RNA, proteins, carbohydrates and lipids. Exposure to SM will cause DNA damage, apoptosis/necrosis and energy crisis in human cells. DNA damage is believed to be the most critical lesion after SM exposure (Batal et al., 2015; Ludlum et al., 1994; Ludlum et al., 1986; Yue et al., 2014). The DNA damage induced by SM is considered to be the most important triggers of cell death in SM 
50

51

52

53

54

55

56

57

58

59

60

61

62

63

64

65

66

67

68

69

70

71

72

73

74

75

76

77

injury. In response to DNA damage, several key biochemical pathways important in protecting cells against injury and initiating repair processes are activated. PARP-1, a nicotine adenine dinucleotide $\left(\mathrm{NAD}^{+}\right.$)-dependent nuclear enzyme implicated in multiple DNA repair pathways (including single strand breaks, double strand breaks and base excision repair), has been shown to be activated upon SM exposure (Hinshaw et al., 1999; Mangerich et al., 2015; Rosenthal et al., 1998). PARP-1 uses $\mathrm{NAD}^{+}$as a substrate to catalyze covalent binding of poly (ADP-ribose) (PAR) to PARP-1 itself and some other nuclear proteins involved in DNA repair, inflammation, apoptosis/ necrosis and autophagy (Sodhi et al., 2010). Although PARP-1 activation had been considered to have a positive effect on cells survival by promoting DNA repair, over activation of PARP-1 initiated by severe SM-induced DNA damage and the consequent depletion of NAD ${ }^{+}$ exacerbated the cell death instead. The $\mathrm{NAD}^{+}$depletion could be prevented by pre-treatment with the PARP inhibitor (Papirmeister et al., 1985). However, little is known about the relationship between the apoptosis and autophagy pathways and the protective effect of PARP-1 inhibitors in SM-induced injury.

Researches on animal models revealed that PARP inhibitor could reduce the pathological damage in the treatment of skin injuries(Casillas et al., 2000; Cowan et al., 2003; Yourick et al., 1991), indicating that PARP inhibitors might have protective effects on SM-induced injury, but the comprehensive pharmacodynamic evaluation of PARP inhibitor for SM injury treatment is still lacking. Actually, there is no further evidence supporting the protective effect of PARP inhibitor on SM injured animal model in nearly 10 years. In vitro, while the cellular NAD ${ }^{+}$ depletion induced by SM injury could indeed be prevented by treatment with PARP inhibitors, the effect on total cell survival could not be observed (Kehe et al., 2008). It is worth noting that, theoretically, PARP inhibition can block DNA repair and increase cell death induced by alkylating agents (Carey and Sharpless, 2011; Xiong et al., 2015). Previous studies also showed that PARP inhibitors indeed delayed the DNA repair in SM injury (Bhat et al., 2006; Bhat et al., 2000). Taken together, the above studies indicated that the role of PARP inhibitor in SM injury is not fully understood, which is definitively worthy of more detailed investigation (Debiak et al., 2009).

In recent years, there is a new generation of PARP inhibitors available in cancer chemotherapy (Coleman et al., 2015; Gunderson and Moore, 2015; Jones et al., 2015; Thomas et al., 2007), which are much more potent than the classical ones. Whether these more specific and potent PARP inhibitors may also be beneficial in treating SM injuries remains to be shown. Therefore, in this study we use ABT-888 hydrochloride, a new generation of PARP inhibitor which is over 100 times more potent than 3-AB (the classical PARP inhibitor that was widely used in treatment of SM injury), as an example to evaluate its effects on immortalized keratinocytes (HaCaT cells) and mouse ear vesicant model (MEVM) treated with SM. Furthermore, we study the mechanism of PARP-1 in SM injury by knockdown of PARP-1 in HaCaT cells.

\section{Materials and Methods}


88

89

90

91

92

93

94

95

96

97

98

99

100

101

102

103

104

105

106

107

108

109

110

111

112

113

114

115

116

117

118

\subsection{Chemicals}

SM (bis-[2-chloroethyl] sulfide, purity 97.6\%) was provided by the Institute of Chemical Defense of CPLA (Chinese People's Liberation Army). ABT-888 hydrochloride (Tian-Xiang et al., 2013) was synthesized in our institute (purity 99\%). The skeletal formula for compound ABT-888 hydrochloride is shown. Other reagents were obtained from Sigma unless otherwise mentioned.<smiles>C[C@]1(c2nc3c(C(N)=O)cccc3[nH]2)CCCN1</smiles>

ABT-888 hydrochloride

2-[(S)-2-methylpyrrolidin-2-yl]-

1H-benzimidazole-4-carboxamide

\subsection{Cells}

Immortalized epithelial keratinocytes ( $\mathrm{HaCaT}$ ) was a spontaneously transformed aneuploid immortal keratinocyte cell line from adult human skin(Boukamp et al., 1988), which was purchased from the China Center for Type Culture Collection (CCTCC) and was cultured in Dulbecco's Modified Eagle Medium/Ham's F12 (DMEM/F12).

\subsection{Detection of PARP-1 enzyme inhibitory activity}

The inhibitory activity of the PARP-1 enzyme was detected using the Trevigen's Homogeneous PARP Inhibition Assay Kit. This assay was performed according to the manufacturer's instructions.

\subsection{Animals}

Twenty-nine adult male Kunming (KM) mice (18-22g) were obtained from the Beijing Vital River Laboratory. The animals were acclimatized for one week before being randomly assigned to experimental groups for use in the experimental studies. The mice were housed in an animal house $\left(26 \pm 2{ }^{\circ} \mathrm{C}\right)$ and were provided with water and food ad libitum throughout the experiment. Briefly, a total of 29 mice were randomly divided into 5 groups: (i) untreated control ( $\mathrm{n}=5$ ), (ii) $0.16 \mathrm{mg} \mathrm{SM} / \mathrm{ear}(\mathrm{n}=5)$, (iii) $0.64 \mathrm{mg} \mathrm{SM} / \mathrm{ear}$ ( $\mathrm{n}=7$ ), (iv) 0.16mg SM/ear + ABT-888 (n=5), and (v) $0.64 \mathrm{mg} \mathrm{SM} /$ ear + ABT-888 $(\mathrm{n}=7)$. The experiments were carried out following protocols approved by the Anima Ethics Committee, Beijing Institute of Pharmacology and Toxicology. The study was conducted according to the Care and Use Guide for Laboratory Animals by the $\mathrm{NIH}$ and was approved by the Bioethics Committee of the Beijing Institute of Pharmacology and Toxicology (No. 80-23). 
119

120

121

122

123

124

125

126

127

128

129

130

131

132

133

134

135

136

137

138

139

140

141

142

143

144

145

146

147

148

149

150

151

152

153

\subsection{Exposure of HaCaT cells to SM}

The exponentially growing $\mathrm{HaCaT}$ cells were seeded in either plates or dishes. Before the exposure to SM, the culture medium was discarded and then 100 or $1000 \mu \mathrm{M}$ SM were added to the plates. After 30 minutes, the agent was removed and the cells were washed with phosphate buffered saline (PBS). DMEM/F12 (with 10\% fetal calf serum) alone or with ABT-888 was added until cells were analyzed as described.

\subsection{Cell viability assay}

Cell viability was quantified using the Cell Counting Kit-8 (CCK-8) (Dojindo). This assay is based on Dojindo's highly water-soluble tetrazolium salt. WST-8 [2-(2-methoxy-4-nitrophenyl)3-(4-nitrophenyl)-5-(2,4-disulfophenyl)-2H-tetrazolium, monosodium salt] is reduced by dehydrogenases in cells to give an orange, water-soluble formazan dye. The amount of the formazan dye generated by dehydrogenases in cells is directly proportional to the number of living cells. Briefly, exponentially growing $\mathrm{HaCaT}$ cells were seeded in 96-well plates at a density of 10,000 cells/well. $6 \mathrm{~h}$ or $24 \mathrm{~h}$ after exposure to SM and the administration of ABT-888, the CCK-8 reagent was added as recommended by the supplier.

\section{7. pADPr immunofluorescence}

$\mathrm{HaCaT}$ cells were seeded in MatTek glass bottom culture dishes and treated with SM and ABT-888. 6h after exposure to SM and the administration of ABT-888, the cells were washed in PBS and fixed in ice cold $100 \%$ methanol for $10 \mathrm{~min}$. The images were obtained by confocal microscopy. The primary antibody used was the anti-pADPr antibody (Abcam) and the secondary antibody was AlexaFluor 488 goat anti-mouse IgG (Molecular Probes). The antibody was dissolved in PBS containing 5\% bovine serum albumin (BSA). Images were obtained using a Zeiss LSM 510 META confocal microscope. The mean fluorescence intensity for pADPr was calculated for each individual nucleus using the PI-marked DNA as a nuclear marker. Approximately 30 cells from three different images were analyzed with the ImageJ program.

\subsection{Acumen}

$\mathrm{HaCaT}$ cells were seeded in 96-well plates and treated with SM. After $6 \mathrm{~h}$ of exposure to SM, the cells were washed with PBS and fixed with 4\% paraformaldehyde for $15 \mathrm{~min}$ and permeabilized in $100 \%$ pre-cooled methanol for $5 \mathrm{~min}$. The cells were then blocked in 5\% BSA and incubated with the anti-pADPr antibody (Abcam) for $1 \mathrm{~h}$ followed by labeling with AlexaFluor 488 goat anti-mouse IgG (Molecular Probes) for $1 \mathrm{~h}$. Then, the cells were stained with $0.3 \mu \mathrm{g} /$ well Hoechst 33342 (Sigma) in PBS for $30 \mathrm{~min}$. The plates were scanned on an Acumen eX3 laser scanning cytometer (TTP LabTech, Melbourne, UK), and the pADPr/nuclear Total Fluorescence Intensity was calculated using the Acumen eX3 software. 
154 Briefly, the cells were washed with cold PBS and lysed on ice for $30 \mathrm{~min}$ in a lysis buffer 155 containing $1 \times$ protease inhibitor cocktail (Roche). The cell lysates were centrifuged at $12000 \times \mathrm{g}$ 156 for $30 \mathrm{~min}$, and the supernatants were collected. The proteins were separated by SDS-PAGE and 157 transferred to NC membranes (Bio-Rad), which were blocked for $2 \mathrm{~h}$ in PBS with 5\% BSA and $1580.1 \%$ Triton X-100. Subsequently, the membranes were incubated with primary antibodies 159 overnight at $4^{\circ} \mathrm{C}$, followed by incubation with the appropriate horseradish peroxidase (HRP)160 labeled secondary antibodies for $2 \mathrm{~h}$ at room temperature. The immunoreactive bands were 161 detected using SuperSignal West Pico Chemiluminescent detection reagents (Thermo 162 SCIENTIFIC). The rabbit anti-PARP-1 antibodies (Cell Signaling Technology), rabbit anti-Actin 163 antibody (Abcam), mouse anti-pADPr antibody (Abcam) and mouse anti-GAPDH antibody (Cell 164 Signaling Technology) were used as primary antibodies.

166 HaCaT cells were seeded in 6-well plates. Six hours or $24 \mathrm{~h}$ after SM exposure and ABT-888 167 administration, the cells were harvested, permeabilized and fixed. The primary antibody was the 168 anti-gamma H2A.X (phospho S139) antibody (Abcam) and the secondary antibody was anti169 rabbit IgG-FITC (Santa Cruz Biotechnology). A FACSCalibur flow cytometer (Becton, 170 Dickinson and Company, BD) was used to detect the fluorescence intensity.

\section{2.11. $N A D^{+}$quantification}

172 Intracellular $\mathrm{NAD}^{+}$levels were measured using the NADH/NAD Quantification kit (Sigma) 173 according to the manufacturer's instructions. Briefly, HaCaT cells were seeded and harvested $6 \mathrm{~h}$ 174 or $24 \mathrm{~h}$ after treatment. Next, cells were extracted with NADH/NAD Extraction Buffer. Total $175 \mathrm{NAD}^{+}$was detected in a 96-well plate following the protocol instructions. The color reaction was read with a $450 \mathrm{~nm}$ filter (Enspire 2300, PERKINELMER, PE).

\subsection{Determination of intracellular ATP}

178 The concentration of intracellular ATP was determined using a bioluminescence ATP assay 179 kit (Beyotime) (Sigma) according to the manufacturer's instructions. Briefly, HaCaT cells were 180 seeded and harvested $6 \mathrm{~h}$ or $24 \mathrm{~h}$ after treatment. The cells were extracted with lysis buffer and 181 an ATP detection working solution was added to each well of a black 96-well plate, followed by 182 incubation for $3 \mathrm{~min}$ at room temperature. Then, the cell lysate samples were added to the wells 183 and the luminescence was measured immediately (Enspire 2300, PE).

\subsection{Measurement of caspase $3 / 7$ activity}

185 Caspase 3/7 activities were measured using the Caspase-Glo 3/7 assay Kit (Promega, Corp.) 186 following manufacturer's instruction. $6 \mathrm{~h}$ or $24 \mathrm{~h}$ after treatment, the HaCaT cells were lysed, 187 and the substrate cleavage by caspase 3/7 was measured from the generated luminescent signal 
188 (Enspire 2300, PE).

\section{2.14. Quantification of apoptotic and necrotic cell death}

190 Apoptosis and necrosis were measured by annexin/propidium iodide (PI) double staining. Six 191 hours or $24 \mathrm{~h}$ after treatment, HaCaT cells were harvested and washed with PBS. Then, the cells 192 were re-suspended in $500 \mu \mathrm{l}$ binding buffer (10 mM HEPES, $140 \mathrm{mM} \mathrm{NaCl}, 2.5 \mathrm{mM} \mathrm{CaCl} 2, \mathrm{pH}$

193 7.4) and stained with $5 \mu \mathrm{l}$ annexin V-FITC and $5 \mu \mathrm{l}$ PI (Invitrogen). The cells were incubated in 194 a dark at room temperature for 15 min according to the manufacturer's instructions and subjected 195 to flow cytometry.

196 2.15. Transient transfection of PARP-1shRNA and selection of stable transfectants

197 The RNAi lentivirus that was used to specifically interfere with the PARP-1 gene was 198 designated PARP-1 ShRNA $\left(5^{\prime}-\right.$ CCGGCGACCTGATCTGGAACATCAACTCGAGTTGATGTTCCAGATCAGGTCGTTTTT$3^{\prime}$ ), and the control shRNA, which was used as the negative control, was designated NC. To establish stable cell lines with knockdown of PARP-1, LV-shPARP-1 was transfected into $\mathrm{HaCaT}$ cells. At $24 \mathrm{~h}$ after transfection, the cells were portioned into new plates and subjected to

203 selection with $3 \mu \mathrm{g} / \mathrm{ml}$ Puromycin (Invitrogen) for 10 days. Independent colonies were isolated and confirmed by western blotting and PCR. Control colonies stably transfected with Lv-shCon were also generated in parallel. Lv-shPARP-1 and Lv-shCon were constructed by BioWit Technologies Co., Ltd (Shenzhen, China).

\subsection{RNA isolation and RT-PCR}

209

210

211

212

213

214

215

216

217

218

219

220

221

222

Total RNA from cultured cells was extracted with Trizol reagent (Invitrogen) according to the manufacturer's instructions. RNA $(1 \mu \mathrm{g})$ was converted to cDNA using the PrimeScript RT reagent kit (Takara Biotechnology). Two sets of primers were used for PCR: GAPDH forward, 5'-AGGTGAAGGTCGGAGTCAAC-3' and reverse, 5'-CGCTCCTGGAAGATGGTGAT-3'; and PARP-1 forward, 5'-GAGCATCCCCAAGGACTCG-3' and reverse, 5'-CCGCTGTCTTCTTGACTTTC-3'. The mRNA expression levels were determined using the SYBR Premix Ex Taq II kit (Takara Biotechnology). The relative mRNA expression of PARP-1 was calculated using the $2-\Delta \Delta \mathrm{Ct}$ method.

\subsection{Luminex assay}

At $6 \mathrm{~h}$ or $24 \mathrm{~h}$ after $\mathrm{SM}$ exposure, HaCaT cells were lysed. The cell suspension was transferred into a centrifuge tube and gently rocked for $10-15$ minutes at $4^{\circ} \mathrm{C}$. Then, the particulate matter was removed by filtration using EMD Millipore filters. The Phospho-JNK (Thr183/Tyr185), Phospho-P53 (ser46), Active Caspase 9 (Asp315), Active Caspase 8 (Asp384), c-PARP (p89), Phospho-AKT (Thr308) and Phospho-mTOR (Ser2448) protein levels were determined with the Luminex assays using a MILLIPLEX MAP (Millipore Corp) according to 
223 the manufacturer's protocols. The data were collected using a Luminex 200 analyzer (Luminex 224 Corp).

225

226

227

228

229

230

231

232

233

234

235

236

237

238

239

240

241

242

243

244

245

246

247

248

249

250

251

252

253

254

255

256

\subsection{Mouse ear vesicant model}

In the mouse ear vesicant model (MEVM), five microliters $(32 \mathrm{mg} / \mathrm{ml}$ and $128 \mathrm{mg} / \mathrm{ml})$ of SM in propylene glycol was applied to the medial surface of the right ears of KM mice. Propylene glycol was applied to the medial surface of the right ear of KM mice in the control group. ABT888 was administered (i.p.) at dose of $200 \mathrm{mg} / \mathrm{kg}$ once $30 \mathrm{~min}$ before or $10 \mathrm{~min}$ after the SM exposure. The injury was measured from the edema response. The ear edema for each animal was initially expressed as a percentage of the increase in relative ear weight (REW) to normal and was calculated from the difference in ear weights between the right and left ears using the following formula:

$$
\% R E W=\frac{S M(\text { or } A B T-888+S M) \text { exposed ear weight }(\text { right ear })-\text { Vehicle control ear weight (left ear })}{\text { Vehicle control ear weight }(\text { left ear })} \times 100
$$

The effect of the drug (modulation of edema) was expressed as the percentage in reduction from the positive control (SM-exposed only) and was calculated from the difference in the mean $\%$ REW between the ABT-888 + SM group and the SM only group (positive control) using the following formula (Babin et al., 2000):

$$
\% \text { Reduction from model }=\frac{(\text { Mean } \% \text { REW ABT }-888+S M)-(\text { Mean } \% \text { REW SM })}{\text { Mean } \% \text { REW SM }} \times 100
$$

\subsection{Histopathology}

Immediately after obtaining the tissue weight, skin punches were fixed in $10 \%$ neutral buffered formalin (NBF). All NBF specimens were embedded in paraffin, sectioned and stained with hematoxylin and eosin $(\mathrm{H} \& \mathrm{E})$ for evaluation.

The histopathological endpoints described in epidermal necrosis (EN; inner surface of the SM treated ear) were given the following severity scores as previously described (Babin et al., 2000): 0 , no lesion or change; 1 , change in $<5 \%$ of the entire tissue section; 2 , change in $10-40 \%$ of the entire tissue section; 3 , change in $50-80 \%$ of the entire tissue section; 4 , change in $>90 \%$ of the entire tissue section. For example, a severity score of 2 (change in $<10 \%-40 \%$ of the entire tissue section) indicates $10 \%-40 \%$ of the epidermal cells are necrotic cells in a $400 \times$ field. Histopathology was evaluated in a blind experiment and the scores were reported as the mean and standard deviation of each group.

\subsection{Statistical analysis}

All values were expressed as the means \pm SEM. For the evaluation of statistical significance, a two-tailed Student's t-test was performed. Bonferroni test was used for post hoc comparison. $P<0.05$ was considered statistically significant.

\section{Results}


257

258

259

260

261

262

263

264

265

266

267

268

269

270

271

272

273

274

275

276

277

278

279

280

281

282

283

284

285

286

287

288

289

290

291

292

293

3.1. PARP-1 activation increased in HaCaT cell following SM treatment, which could be prevented by $A B T-888$

SM is a highly reactive bifunctional alkylating agent that induces DNA damage. DNA damage activates PARP-1, which catalyzes the transfer of ADP-ribose units from nicotinamide adenine dinucleotide $\left(\mathrm{NAD}^{+}\right)$to PARP-1 itself and a range of other nuclear proteins. To determine the activation of PARP-1 and the PARP inhibitory activity of ABT-888 in SM treated HaCaT cells, the expression of pADPr was detected by immunofluorescence and western blotting. The increase of pADPr, which represented the activation of PARP-1, was observed after $6 \mathrm{~h}$ of exposure to SM at concentrations of either $100 \mu \mathrm{M}$ or $1000 \mu \mathrm{M}$. The activation of PARP-1 under $1000 \mu \mathrm{M}$ SM exposure was much greater than under $100 \mu \mathrm{M}$ SM exposure. Immediate application of ABT-888 after SM exposure could significantly decrease the expression of pADPr, especially under $1000 \mu \mathrm{M}$ SM exposure. In addition, ABT-888 alone group and control group did not show any significant difference in the expression of pADPr (Fig. 1A-1E). These results suggested that the SM injury could cause PARP-1 activation, which could be marked inhibited by the potent PARP inhibitor ABT-888. The PARP-1 inhibitory effect of ABT-888 was also confirmed using the Trevigen's Homogeneous PARP Inhibition Assay Kit (Fig. 1F).

\subsection{PARP inhibitor ABT-888 had a protective effect in HaCaT cells after severe SM injury}

In HaCaT cells, at $6 \mathrm{~h}$ post-treatment by ABT-888, cell viability was significantly increased under $1000 \mu \mathrm{M}$ SM exposure (Fig. 2A), whereas ABT-888 did not protect cell viability under $100 \mu \mathrm{M}$ SM exposure. Moreover, the addition of ABT-888 no longer showed the protective effect at $24 \mathrm{~h}$ post SM exposure (Fig. 2B). ABT-888 alone group and control group did not show any significant difference in cell viability.

\subsection{PARP inhibitor ABT-888 had a protective effect in mouse ear vesicant model after severe} SM injury

In the SM-induced mouse ear vesicant model, we also observed protective effect of ABT-888. ABT- 888 showed a protective effect in severe SM injury. The structural alterations of the skin in the mouse ears post SM exposure were observed. Exposure to $0.16 \mathrm{mg} \mathrm{SM} / \mathrm{ear}$ and $0.64 \mathrm{mg}$ $\mathrm{SM} /$ ar resulted in moderate to severe edema and epidermal necrosis at 24 hour after SM exposure. Twenty-four hours post-exposure to $0.16 \mathrm{mg} \mathrm{SM} /$ ear and $0.64 \mathrm{mg} \mathrm{SM} /$ ear, the dermis inflammatory cell infiltration and reticular degenerative changes associated with basal cell necrosis of the epidermis were observed, along with hypereosinophilic cytoplasms and nuclear pyknosis. Epidermal cells exposed to $0.16 \mathrm{mg}$ SM/ear showed pyknotic nuclei, but ABT-888 did not show any protective effect. More pyknotic nuclei of epidermal cells were observed in the mouse ear skin exposed to $0.64 \mathrm{mg} \mathrm{SM} /$ ear than that exposed to $0.16 \mathrm{mg} \mathrm{SM} / \mathrm{ear}$ and ABT-888 could significantly reduce the number of pyknotic nuclei (Fig. 3A).

The increase in relative ear weight (REW) to normal represented the ear edema. The REW and epidermal necrosis (EN) scores for the right ear of each animal in the control group were zero 
294 (Tab. S3). The REW and EN scores of all SM groups were significantly different from those of 295 the control group, and the scores of the group exposed to $0.64 \mathrm{mg} \mathrm{SM} / \mathrm{ear}$ (REW 204\%, EN 3.9) 296 were higher than those of the group exposed to $0.16 \mathrm{mg} \mathrm{SM} / \mathrm{ear}$ (REW 154\%, EN 2.2). ABT-888 297 did not reduce the REW and EN scores in the group exposed to $0.16 \mathrm{mg} \mathrm{SM} /$ ear, but ABT-888 298 reduced the REW (approximately 26\%) and EN scores (approximately 40\%) in the group

299

300

301

302

303

304

305

306

307

308

309

310

311

312

313

314

315

316

317

318

319

320

321

322

323

324

325

326

327

328

329

330 exposed to $0.64 \mathrm{mg} \mathrm{SM} /$ ear (Fig. 3B and 3C). The results were similar when ABT-888 was applied either after or before SM treatment (Tab. S10). In addition, ABT-888 alone group and control group did not show any significant difference (Tab. S10).

3.4. The PARP inhibitor ABT-888 could prevent the reduction of $N A D^{+}$and ATP in HaCaT cell after SM exposure

SM has been shown to activate the enzymatic activity of PARP-1 by decreasing the NAD ${ }^{+}$ concentration in either human skin grafts (Gross et al., 1985) or keratinocytes ex vivo (Rosenthal et al., 1998). Severe SM-induced DNA damage over-activates PARP-1, leading to the depletion of $\mathrm{NAD}^{+}$and ATP. To determine the $\mathrm{NAD}^{+}$and ATP concentration after SM exposure and the effect of ABT-888, HaCaT cells were exposed to SM and the concentrations of intracellular $\mathrm{NAD}^{+}$and ATP were measured 6 and 24 hours later. SM exposure could decrease $\mathrm{NAD}^{+}$and ATP levels (Fig. 4A-4D). ABT-888 alone group and control group did not show any significant difference in $\mathrm{NAD}^{+}$and $\mathrm{ATP}$ concentration. Immediate application of ABT-888 after SM exposure could prevent the reduction of $\mathrm{NAD}^{+}$and ATP.

3.5. The PARP inhibitor ABT-888 suppressed SM-induced apoptosis and necrosis in HaCaT cells.

It has been known that SM-induced DNA injury causes PARP activation, which may lead to necrosis or apoptosis. PARP-1 has been shown to participate in apoptotic and necrotic cell death pathways. Therefore, we used flow cytometry to analysis HaCaT cells doubly stained for annexin V and PI to observe the SM-induced apoptosis and necrosis and to assess the effect of ABT-888. The results showed that only $1000 \mu \mathrm{M}$ SM caused HaCaT cell apoptosis and necrosis after SM exposure. ABT-888 significantly decreased the percentage of apoptotic and necrotic cells (Fig. 5E and 5F).

Thus, we next assessed whether SM activates the caspase-PARP pathway, which is the main executor of apoptotic processes. Caspase-3/7 is responsible for the cleavage of PARP-1 during apoptosis. Therefore, the caspase-3/7 activity was measured after treatment of HaCaT cells with 100 or $1000 \mu \mathrm{M}$ SM for $6 \mathrm{~h}$ or $24 \mathrm{~h}$. At $6 \mathrm{~h}$ following 100 or $1000 \mu \mathrm{M}$ SM exposure, an increase in caspase-3/7 activity was observed. ABT-888 decreased caspase 3/7 activity in cells exposed to $1000 \mu \mathrm{M}$ SM but increased caspase $3 / 7$ activity in cells exposed to $100 \mu \mathrm{M}$ SM (Fig. 5A). At 24 $\mathrm{h}$ following SM exposure, ABT-888 decreased the caspase 3/7 activity in HaCaT cells (Fig. 5B).

When apoptosis occurs, PARP-1 is cleaved by activated caspase 3/7 into p89 and p24 fragments. To observe the effects of ABT-888 on apoptosis at different doses and incubation 
331 times with SM, a western blot was performed to detect c-PARP (cleavage of PARP-1, an

332 apoptosis-specific p89 fragment). The results showed that SM could significantly increase the 333 expression of c-PARP. At $6 \mathrm{~h}$ after $1000 \mu \mathrm{M}$ SM exposure, ABT-888 decreased the expression

334 of c-PARP. However, ABT-888 showed no significant effect on c-PARP levels in cells exposed 335 to $100 \mu \mathrm{M}$ SM (Fig. 5C). However, ABT-888 had no significant protective effects on c-PARP 336 levels at $24 \mathrm{~h}$ after SM exposure (Fig. 5D). In addition, ABT-888 alone group and control group 337 did not show any significant difference in caspase-3/7 activity, c-PARP levels, percentage of 338 apoptotic and necrotic cells.

339

340

341

342

343

344

345

346

347

348

349

350

351

352

353

354

355

356

357

358

359

360

361

362

363

364

365

366

\subsection{PARP-1 knockdown protected HaCaT cells from SM-induced cell death}

To further investigate the mechanism of PARP-1 on the toxicity of SM, we used RNA interference to knock down the endogenous PARP-1 in HaCaT cells. To examine the effect of PARP-1 knockdown on the mRNA level, the total mRNA from control and PARP-knockdown HaCaT cells was isolated and processed for RT-PCR. The relative mRNA expression of PARP-1 was calculated. The results showed that PARP-1 shRNA significantly decreased the levels of PARP-1 mRNA by $90 \%$ compared to the level in the control (Fig. 6A). The level of PARP-1 protein was also significantly decreased by RNA interference (Fig. 6B).

To study the effect of PARP-1 knockdown in the toxicity of SM, we examined the cell viability in PARP-1-knock-down and control HaCaT cells exposed to SM using the CCK-8 kit. The results showed that 100 or $1000 \mu \mathrm{M}$ SM exposure decreased the cell viability $6 \mathrm{~h}$ and $24 \mathrm{~h}$ after SM treatment. The downregulation of PARP-1 significantly increased cell viability compared with that of the control SM-treated cells (Fig. 6C and 6D), suggesting that PARP-1 knockdown suppressed the toxicity of SM at the level of cell viability.

3.7. PARP-1 knockdown suppressed the SM-induced apoptosis checkpoint signals in HaCaT cells

In $\mathrm{HaCaT}$ cells treated with NC shRNA, the protein levels of phospho-JNK (Thr183/Tyr185), phospho-P53 (ser46), active Caspase 9 (Asp315), active Caspase 8 (Asp384), c-PARP (p89) and Caspase 3/7 activity were enhanced in response to SM stimulation (Fig. 7A-7L). However, $24 \mathrm{~h}$ after exposure to $1000 \mu \mathrm{M}$ SM, the protein levels of phospho-JNK (Thr183/Tyr185) (Fig. 7B), phospho-P53 (ser46) (Fig. 7D), active Caspase 9 (Asp315) (Fig. 7F), and active Caspase 8 (Asp384) (Fig. 7H) were extremely low, possibly because these early apoptosis signals could not be detected during the late apoptosis. In the HaCaT cells treated with PARP-1 shRNA, all of the apoptosis checkpoint signals mentioned above was downregulated compared to the cells treated with NC shRNA (Fig. 7A-7L). These results suggested that the silencing of PARP-1 suppressed the SM-induced apoptosis checkpoint signals in the HaCaT cells.

\subsection{PARP-1 knockdown reversed the SM-induced suppression of the Akt/mTOR pathway}

Previously, it was reported that PARP-1 is involved in autophagy induced by DNA damage 
367 through the activation of the key autophagy regulator mTOR (Munoz-Gamez et al., 2009). To

368 investigate whether SM exposure activated mTOR and how PARP-1 participated in this process, 369 the phosphorylation of Akt and mTOR was evaluated in PARP-1-knockdown and NC HaCaT

370

371

372

373

374

375

376

377

378

379

380

381

382

383

384

385

386

387

388

389

390

391

392

393

394

395

396

397

398

399

400

401

402

403

cells. The results showed that in the HaCaT cells treated with NC shRNA, the phosphorylation of Akt and mTOR was suppressed in response to SM stimulation (Fig. 8B, 8D). At $24 \mathrm{~h}$ after exposure of HaCaT cells to SM, PARP-1 knockdown significantly increased the phosphorylation of Akt and mTOR (Fig. 8B, 8D), whereas PARP-1 knockdown had no effect on the phosphorylation of Akt and mTOR at $6 \mathrm{~h}$ after exposure to SM (Fig. 8A, 8C). The results suggested that PARP-1 knockdown reversed the SM-induced suppression of the Akt/mTOR pathway, which might affect autophagy following SM-induced injury. Taken together, the results suggest that the silencing of PARP-1 could protect HaCaT cell from SM-induced injury by regulating the apoptosis and autophagy pathways.

\subsection{PARP inhibitor ABT-888 further enhanced the DNA damage after SM exposure}

H2AX is a sensitive marker for DNA double-stranded breaks (DSB) (Fernandez-Capetillo et al., 2004). When DSB occurs, H2AX is phosphorylated at Ser139 in the nucleosomes surrounding the break point (Thiriet and Hayes, 2005). To determine the effect of SM on DNA damage and the potential effect of ABT-888 on preventing SM injury, the phosphorylation of $\mathrm{H} 2 \mathrm{AX}$ (S139) was detected in HaCaT cells. HaCaT cells were exposed to $100 \mu \mathrm{M}$ or $1000 \mu \mathrm{M}$ SM before DMEM/F12 (with 10\% fetal calf serum) alone or with $10 \mu \mathrm{M}$ ABT-888 was added. The cells were then analyzed by flow cytometry. The results showed that exposure to $100 \mu \mathrm{M}$ and $1000 \mu \mathrm{M}$ SM increased the phosphorylation of H2AX in HaCaT cells at both $6 \mathrm{~h}$ (Fig. 9A) and $24 \mathrm{~h}$ (Fig. 9B) following SM exposure. ABT-888 enhanced the phosphorylation of H2AX caused by SM exposure at $24 \mathrm{~h}$ (Fig. 9B). This result indicated that PARP inhibitor actually increased the DNA damage after SM exposure.

\section{Discussion}

Due to the multiple actions of PARP-1 on SM-induced injury, the potential use of PARP inhibitors have drawn much attention in SM therapy (Debiak et al., 2009; Kehe et al., 2008; Rosenthal et al., 2001; Steinritz et al., 2007). In recent years, new generation of specific and potent PARP inhibitors in cancer chemotherapy (Coleman et al., 2015; Gunderson and Moore, 2015; Jones et al., 2015; Thomas et al., 2007) provides more selective choices on treating SM injury. ABT-888 is one of the new PARP inhibitor which is over 100 times more potent than the classical PARP inhibitor 3-AB. In this study, we evaluate the effect of PARP inhibitor ABT-888 in HaCaT cells and MEVM treated with SM, and study the mechanism of PARP-1 in SM injury by knockdown of PARP-1 in HaCaT cells.

According to our findings, the application of ABT-888 could reduce pathological damage after severe SM injury $(0.64 \mathrm{mg} \mathrm{SM} /$ ear) in MEVM, which is consistent with the results of other groups (Cowan et al., 2003; Yourick et al., 1991). Besides the reduction on pathological damage, 
404 ABT-888 could also reduce edema after severe SM injury in MEVM according to our results, 405 which suggested that ABT-888 may have more therapeutic value in the treatment of skin injuries. 406 Furthermore, we found that ABT-888 showed no protective effect against mild SM-induced 407 injury (0.16mg SM/ear).

408 Consistent with the results of the MEVM experiments, we also found that PARP-1 inhibition 409 had a cytoprotective effect on HaCaT cells. ABT-888 significantly increased cell viability at $6 \mathrm{~h}$ 410 after severe SM injury (1000 $\mu \mathrm{M}$ SM exposure), whereas ABT-888 did not protect cell viability 411 under mild SM injury (100 $\mu$ M SM exposure), suggesting that ABT-888 shows protective effects 412 only at early times after severe SM injury. However, the protective effects could not be observed 413 after $24 \mathrm{~h}$ exposure, which is consistent with the results of other groups using the classic PARP 414 inhibitor 3-AB (Kehe et al., 2008). The results from our study in MEVM and HaCaT model 415 indicated that the new generation of specific and potent PARP inhibitor ABT-888 had more 416 protective effect than other PARP inhibitors which were used in treatment of SM injury (Cowan 417 et al., 2003; Kehe et al., 2008).

418 To investigate the reason why the PARP inhibitor showed protective effects after SM injury, 419 we studied the role of PARP-1 in the SM-induced injury in HaCaT cells. Our results showed that 420 the expression of pADPr increased in HaCaT cells after $6 \mathrm{~h}$ exposure to either $100 \mu \mathrm{M}$ or 1000 $421 \mu \mathrm{M}$ SM, and the expression of pADPr increased much more in the cells exposed to $1000 \mu \mathrm{M}$ SM 422 than those exposed to $100 \mu \mathrm{M}$ SM. Our results were consistent with other researchers' findings (Bhat et al., 2006; Mangerich et al., 2015; Mol et al., 1989). In addition, our present study 424 demonstrated that SM exposure significantly decreased $\mathrm{NAD}^{+}$and $\mathrm{ATP}$ levels, consistenting with the Papirmeister and colleagues' finding that severe SM-induced DNA damage overactivated PARP-1, leading to the depletion of $\mathrm{NAD}^{+}$, the protease release and the blister formation (Gross et al., 1985; Papirmeister et al., 1985). PARP inhibitor ABT-888 inhibited SMinduced PARP-1 activation. Severe SM injury could cause $\mathrm{NAD}^{+}$exhaustion, whereas mild SM injury only consumed $\mathrm{NAD}^{+}$. The immediate application of ABT-888 after SM exposure could prevent the $\mathrm{NAD}^{+}$and ATP reduction after SM exposure.

In addition to its major role in responding to DNA damage, PARP-1 is also an important mediator of apoptotic and/or necrotic pathways (Aredia and Scovassi, 2014; Dantzer et al., 2000; Marchenko et al., 2000). The cell death pathway involving PARP-1 plays a pivotal role in tissue injury and organ dysfunction in SM-induced toxicity (Kehe et al., 2008; Korkmaz et al., 2008). PARP-1 triggers necrotic cell death due to the rapid consumption of the substrate $\mathrm{NAD}^{+}$, leading to ATP depletion (Los et al., 2002). In addition, PARP-1 is involved in a caspase-independent apoptosis pathway mediated by apoptosis-inducing factor. Our flow cytometry results showed that SM could induce apoptosis and necrosis in HaCaT cells. ABT-888 significantly decreased the percentage of apoptotic and necrotic HaCaT cells exposed SM. N-methyl-N-nitro-Nnitrosoguanidine (MNNG) is a DNA-alkylating agent. Seong-Woon Yu et al. showed that treatment with $\mathrm{MNNG}$ could cause annexin-V staining. Annexin-V staining was not observed in PARP-1-KO fibroblasts ( $\mathrm{Yu}$ et al., 2002), which is consistent with our results that PARP 
443

444

445

446

447

448

449

450

451

452

453

454

455

456

457

458

459

460

461

462

463

464

465

466

467

468

469

470

471

472

473

474

475

476

477

478

479

480

481

inhibition could reduce the apoptosis induced by alkylating agents.

Caspase-3-catalysed PARP-1 degradation is one of the major events during SM-induced apoptosis. The ability of PARP-1 to repair DNA damage is prevented by the cleavage of PARP-1 by caspase $3 / 7$, a process that plays a central role in the apoptotic pathway and is reported to be involved in SM-induced toxicity (Debiak et al., 2009; Mol et al., 2009). The specific cleavage of PARP-1 by caspase-3/7 and the generation of 89 and $24 \mathrm{kDa}$ fragments have been extensively used as a biochemical marker of caspase-dependent apoptosis(Decker and Muller, 2002). At $6 \mathrm{~h}$ after exposure to $1000 \mu \mathrm{M}$ SM, western blot analysis revealed marked PARP-1 cleavage into the $89-\mathrm{kDa}$ fragment (c-PARP), while exposure to $100 \mu \mathrm{M}$ SM showed no PARP-1 cleavage. ABT888 could decrease c-PARP expression and caspase 3/7 activation at $6 \mathrm{~h}$ after exposure to 1000 $\mu \mathrm{M}$ SM, but showed no effect in cells exposed to $100 \mu \mathrm{M}$ SM. However, there were no significant protective effects on expression of c-PARP at $24 \mathrm{~h}$ after SM exposure.

To further investigate the mechanism of PARP-1 in SM injury, stable PARP-1 knockdown $\mathrm{HaCaT}$ cells were constructed using RNA interference. We found evidence that PARP-1 knockdown in HaCaT cell lines resulted in an increase in cell viability after SM exposure, which was consistent with our previous work.

It has been shown that the protective effect of a PARP-1 inhibitor in SM-induced injury is mainly due to a mitigation of the $\mathrm{NAD}^{+}$depletion caused by SM poisoning (Hinshaw et al., 1999; Meier et al., 1987; Mol et al., 1989; Smith et al., 1990). However, PARP-1 is involved in many other important pathological functions, including apoptosis and autophagy (Virag et al., 2013), in addition to its important role in cellular energy. PARP-1 is involved in a caspase-independent apoptosis pathway based on the nuclear-to-mitochondrial translocation of pADPr, which triggers the reverse (mitochondrial-to nuclear) translocation of an apoptosis-inducing factor (AIF) (Wang et al., 2009). The MAP kinase pathway or the PI3-kinase-Akt pathway have also been shown to be involved in PARP-1 activation (Aredia and Scovassi, 2014). Moreover, it has become increasingly clear that p53 is directly regulated by poly(ADP-ribose) polymerase-1 (PARP-1) (Elkholi and Chipuk, 2014). To investigate whether the activation of PARP-1 is involved in SMinduced apoptosis, we exposed control and PARP-1-knockdown HaCaT cells to SM and measured the phospho-JNK (Thr183/Tyr185), phospho-P53 (ser46), active caspase 9 (Asp315), active caspase 8 (Asp384), c-PARP (p89) and caspase 3/7 activity. Our data showed that SM activated the apoptosis checkpoints mentioned above and that PARP-1 knockdown suppressed the SM-induced apoptosis checkpoint signals in HaCaT cells, suggesting that PARP-1 knockdown may protect $\mathrm{HaCaT}$ cells from SM-induced injury via downregulation of the apoptosis pathway.

Autophagy is a homeostatic "self-eating" pathway that has been conserved among eukaryotic cells (Klionsky and Emr, 2000). Autophagy is a defense mechanism for the disposal of damaged organelles or misfolded proteins that protects damaged cells. It is also a type of cell death pathway that induces active cell death (Navarro-Yepes et al., 2014). mTOR is a serine/threonine kinase that is highly conserved in all eukaryotes and plays a key role in regulating autophagy. 
482 This kinase is a central regulator of cell growth and a major nutrient sensor, and the inhibition of 483 mTOR can induce autophagy (Kim and Guan, 2015). The PI3K/AKT pathway is the upstream 484 regulator of mTOR, and the activation of AKT can inhibit autophagy via the regulation of mTOR 485 (Meijer and Codogno, 2006). It has been reported that PARP-1 deficiency can reduce autophagy 486 due, in part, to the lack of inhibition of mTOR (Virag et al., 2013). However, the effect of PARP4871 deficiency on the AKT/mTOR pathway in SM-induced injury is still unknown. Our results 488 showed that SM exposure could significantly inhibit the activation of the AKT/mTOR pathway 489 and that PARP-1 knockdown, to a certain extent, reversed the toxicity of SM. The results indicated that the activation of PARP-1 may be involved in the inhibition of the AKT/mTOR pathway induced by SM and that inhibition of PARP-1 may inhibit autophagy by re-activating the AKT/mTOR pathway.

In this study, some biological parameters of control and samples treated with the $100 \mu \mathrm{M} \mathrm{SM}$ at $6 \mathrm{~h}$ are not significantly different, such as ATP, apoptosis/necrosis cells (\%), p-p53, active Caspase 9, active Caspase 8, c-PARP and p-mTOR. This may be the reason why no effect of PARP-1 inhibition is observed in these biological parameters since the effect of SM in cells exposed to $100 \mu \mathrm{M}$ is not very high.

It should be noticed that PARP inhibitors could enhance DNA damage when applied to cancer cells exposed to DNA damaging agents. A similar phenomenon for the application of PARP inhibitors in SM injury has been reported by Bhat et al. (Bhat et al., 2006; Bhat et al., 2000). In their study, primary keratinocytes displayed rapid phosphorylation and activation of DNA ligase I, a DNA repair enzyme, after SM exposure, and the half-life of activated DNA ligase I increased from 1.3 to $4.3 \mathrm{~h}$ in the presence of the PARP inhibitor 3-AB, which implied that the PARP inhibitor could delay the DNA repair in SM injury. Nevertheless, the authors did not provide direct evidence that PARP inhibition could increase DNA damage in SM injury(Debiak et al., 2009). In our study, we obtained evidence that PARP-1 involved in the repairment of DNA damage induced by SM. H2AX is rapidly phosphorylated following double-strand DNA breaks, which is a key step in activating the DNA damage response pathways that are important in repair (Mah et al., 2010). Our results showed that exposure to either $100 \mu \mathrm{M}$ or $1000 \mu \mathrm{M}$ SM increased the phosphorylation of $\mathrm{H} 2 \mathrm{AX}$ (gamma-H2AX) in HaCaT cells. However, SM does not directly induce double-strand breaks (Kehe et al., 2009). SM exposure will lead to the formation of unstable adducts that are partly converted into abasic sites and single strand-breaks (Batal et al., 2014). Abasic sites and single strand-breaks can then give rise to double strand breaks through indirect mechanisms such as the collapse of replication forks (Andreassen et al., 2006). According to our results, ABT-888 further enhanced double strand breaks, which could be explained by the fact that cellular toxicity was decreased by ABT- 888 and that more cell divide in the treated samples. Our results indicated that although PARP inhibitor could prevent cell death induced by SM, the increased genotoxicity and likely mutagenesis caused by PARP inhibition should also be considered.

In our study, $\mathrm{HaCaT}$ cells were utilized as an in vitro cell model to study the toxicity of SM in 
521 skin injuries, and discuss the mechanism how PARP-1 inhibitor exerts its efficacy in SM injury.

522 The HaCaT cell line is a spontaneously transformed human epithelial cell line, which is

523 commonly used for skin toxicity testing and the study of SM-induced apoptosis and skin injuries

524 (Heinrich et al., 2009; Kehe et al., 2008; Wolf et al., 2015). But as we know, HaCaT cells have a

525 mutated p53 background (Lehman et al., 1993). This may represent a limitation for extrapolation

526 of the present results to human skin cells. However, in the present study we did observe a

527 protective effect of PARP-1 inhibitor in MEVM, indicating that the protective effect of PARP-1

528 inhibitor could be observed not only in HaCaT cell line but also in normal mouse skin. But still,

529 in order to better reveal the role of PARP-1 in SM induced skin injuries, the effect of PARP-1

530 inhibitor in SM-exposed primary cultured of human keratinocyte will be investigated in our

531 laboratory in the future study.

\section{5. Conclusions}

533 In conclusion, we demonstrated that ABT-888, a new generation of specific and potent PARP 534 inhibitor, had a therapeutic effect in mouse ear vesicant model (MEVM) and HaCaT cell model 535 after severe SM injury. ABT-888 could reduce SM-induced NAD ${ }^{+}$ATP depletion and 536 apoptosis/necrosis in HaCaT cell model. Furthermore, PARP-1 knockdown protects HaCaT cells 537 from sulfur mustard-induced injury by regulating the apoptosis and autophagy checkpoints. 538 Taken together, our results indicated that protective effects of downregulation of PARP-1 in SM 539 injury may be due to the mitigation of apoptosis, necrosis, energy crisis and autophagy. However, 540 PARP inhibitor ABT-888 further enhanced the DNA damage after SM exposure, which 541 indicated that we should be very careful in the application of PARP inhibitors in SM injury 542 treatment (Fig. 10). In addition, the mechanism by which PARP-1 inhibition is protective against 543 SM-induced injury is mainly focused on the mitigation of the $\mathrm{NAD}^{+}$depletion. However, based 544 on the evidence provided in this article, we have reason to believe that the effect of PARP-1 in 545 the apoptosis and autophagy pathways in sulfur mustard-induced injury cannot be ignored. This 546 study provided a new theoretical basis for PARP-1 inhibition in the treatment of sulfur mustard547 induced injuries.

\section{Acknowledgments}

549 We would like to thank Mrs. Xu Xin for the technical assistance.

\section{References}

Andreassen, P. R., Ho, G. P., and D'Andrea, A. D. (2006). DNA damage responses and their many interactions with the replication fork. Carcinogenesis 27, 883-892.

553

554

Aredia, F., and Scovassi, A. I. (2014). Poly(ADP-ribose): a signaling molecule in different paradigms of cell death. Biochemical pharmacology 92, 157-163.

Babin, M. C., Ricketts, K., Skvorak, J. P., Gazaway, M., Mitcheltree, L. W., and Casillas, R. P. (2000). Systemic administration of candidate antivesicants to protect against topically applied sulfur mustard in the mouse ear 
557

558

559

560

561

562

563

564

565

566

567

568

569

570

571

572

573

574

575

576

577

578

579

580

581

582

583

584

585

586

587

588

589

590

591

592

593

594

595

vesicant model (MEVM). Journal of applied toxicology : JAT 20 Suppl 1, S141-144.

Balali-Mood, M., and Hefazi, M. (2005). The pharmacology, toxicology, and medical treatment of sulphur mustard poisoning. Fundamental \& clinical pharmacology 19, 297-315.

Balali-Mood, M., and Hefazi, M. (2006). Comparison of early and late toxic effects of sulfur mustard in Iranian veterans. Basic \& clinical pharmacology \& toxicology 99, 273-282.

Batal, M., Boudry, I., Mouret, S., Clery-Barraud, C., Wartelle, J., Berard, I., and Douki, T. (2014). DNA damage in internal organs after cutaneous exposure to sulphur mustard. Toxicology and applied pharmacology 278, 39-44.

Batal, M., Rebelo-Moreira, S., Hamon, N., Bayle, P. A., Mouret, S., Clery-Barraud, C., Boudry, I., and Douki, T. (2015). A guanine-ethylthioethyl-glutathione adduct as a major DNA lesion in the skin and in organs of mice exposed to sulfur mustard. Toxicology letters 233, 1-7.

Bhat, K. R., Benton, B. J., and Ray, R. (2006). Poly (ADP-ribose) polymerase (PARP) is essential for sulfur mustardinduced DNA damage repair, but has no role in DNA ligase activation. Journal of applied toxicology : JAT 26, 452457.

Bhat, K. R., Benton, B. J., Rosenthal, D. S., Smulson, M. E., and Ray, R. (2000). Role of poly(ADP-ribose) polymerase (PARP) in DNA repair in sulfur mustard-exposed normal human epidermal keratinocytes (NHEK). Journal of applied toxicology : JAT 20 Suppl 1, S13-17.

Boukamp, P., Petrussevska, R. T., Breitkreutz, D., Hornung, J., Markham, A., and Fusenig, N. E. (1988). Normal keratinization in a spontaneously immortalized aneuploid human keratinocyte cell line. The Journal of cell biology $106,761-771$.

Carey, L. A., and Sharpless, N. E. (2011). PARP and cancer--if it's broke, don't fix it. The New England journal of medicine 364, 277-279.

Casillas, R. P., Kiser, R. C., Truxall, J. A., Singer, A. W., Shumaker, S. M., Niemuth, N. A., Ricketts, K. M., Mitcheltree, L. W., Castrejon, L. R., and Blank, J. A. (2000). Therapeutic approaches to dermatotoxicity by sulfur mustard. I. Modulaton of sulfur mustard-induced cutaneous injury in the mouse ear vesicant model. Journal of applied toxicology : JAT 20 Suppl 1, S145-151.

Coleman, R. L., Sill, M. W., Bell-McGuinn, K., Aghajanian, C., Gray, H. J., Tewari, K. S., Rubin, S. C., Rutherford, T. J., Chan, J. K., Chen, A., and Swisher, E. M. (2015). A phase II evaluation of the potent, highly selective PARP inhibitor veliparib in the treatment of persistent or recurrent epithelial ovarian, fallopian tube, or primary peritoneal cancer in patients who carry a germline BRCA1 or BRCA2 mutation - An NRG Oncology/Gynecologic Oncology Group study. Gynecologic oncology.

Cowan, F. M., Broomfield, C. A., Lenz, D. E., and Smith, W. J. (2003). Putative role of proteolysis and inflammatory response in the toxicity of nerve and blister chemical warfare agents: implications for multi-threat medical countermeasures. Journal of applied toxicology : JAT 23, 177-186.

Dantzer, F., de La Rubia, G., Menissier-De Murcia, J., Hostomsky, Z., de Murcia, G., and Schreiber, V. (2000). Base excision repair is impaired in mammalian cells lacking Poly(ADP-ribose) polymerase-1. Biochemistry 39, 7559-7569.

Debiak, M., Kehe, K., and Burkle, A. (2009). Role of poly(ADP-ribose) polymerase in sulfur mustard toxicity. Toxicology 263, 20-25.

Decker, P., and Muller, S. (2002). Modulating poly (ADP-ribose) polymerase activity: potential for the prevention and therapy of pathogenic situations involving DNA damage and oxidative stress. Current pharmaceutical 
596

597

598

599

600

601

602

603

604

605

606

607

608

609

610

611

612

613

614

615

616

617

618

619

620

621

622

623

624

625

626

627

628

629

630

631

632

633

634

biotechnology 3, 275-283.

Elkholi, R., and Chipuk, J. E. (2014). How do I kill thee? Let me count the ways: p53 regulates PARP-1 dependent necrosis. BioEssays : news and reviews in molecular, cellular and developmental biology 36, 46-51.

Fernandez-Capetillo, O., Lee, A., Nussenzweig, M., and Nussenzweig, A. (2004). H2AX: the histone guardian of the genome. DNA repair 3, 959-967.

Ghanei, M., Poursaleh, Z., Harandi, A. A., Emadi, S. E., and Emadi, S. N. (2010). Acute and chronic effects of sulfur mustard on the skin: a comprehensive review. Cutaneous and ocular toxicology 29, 269-277.

Gross, C. L., Meier, H. L., Papirmeister, B., Brinkley, F. B., and Johnson, J. B. (1985). Sulfur mustard lowers nicotinamide adenine dinucleotide concentrations in human skin grafted to athymic nude mice. Toxicology and applied pharmacology 81, 85-90.

Gunderson, C. C., and Moore, K. N. (2015). Olaparib: an oral PARP-1 and PARP-2 inhibitor with promising activity in ovarian cancer. Future Oncol 11, 747-757.

Hanaoka, S., Nomura, K., and Wada, T. (2006). Determination of mustard and lewisite related compounds in abandoned chemical weapons (Yellow shells) from sources in China and Japan. Journal of chromatography A 1101, 268-277.

Heinrich, A., Balszuweit, F., Thiermann, H., and Kehe, K. (2009). Rapid simultaneous determination of apoptosis, necrosis, and viability in sulfur mustard exposed HaCaT cell cultures. Toxicology letters 191, 260-267.

Hinshaw, D. B., Lodhi, I. J., Hurley, L. L., Atkins, K. B., and Dabrowska, M. I. (1999). Activation of poly [ADP-Ribose] polymerase in endothelial cells and keratinocytes: role in an in vitro model of sulfur mustard-mediated vesication. Toxicology and applied pharmacology 156, 17-29.

Jones, P., Wilcoxen, K., Rowley, M., and Toniatti, C. (2015). Niraparib: A Poly(ADP-ribose) Polymerase (PARP) Inhibitor for the Treatment of Tumors with Defective Homologous Recombination. Journal of medicinal chemistry.

Kehe, K., Balszuweit, F., Steinritz, D., and Thiermann, H. (2009). Molecular toxicology of sulfur mustard-induced cutaneous inflammation and blistering. Toxicology 263, 12-19.

Kehe, K., Raithel, K., Kreppel, H., Jochum, M., Worek, F., and Thiermann, H. (2008). Inhibition of poly(ADP-ribose) polymerase (PARP) influences the mode of sulfur mustard (SM)-induced cell death in HaCaT cells. Archives of toxicology $82,461-470$.

Kim, Y. C., and Guan, K. L. (2015). mTOR: a pharmacologic target for autophagy regulation. The Journal of clinical investigation 125, 25-32.

Klionsky, D. J., and Emr, S. D. (2000). Autophagy as a regulated pathway of cellular degradation. Science (New York, NY) 290, 1717-1721.

Korkmaz, A., Tan, D. X., and Reiter, R. J. (2008). Acute and delayed sulfur mustard toxicity; novel mechanisms and future studies. Interdisciplinary toxicology 1, 22-26.

Lehman, T. A., Modali, R., Boukamp, P., Stanek, J., Bennett, W. P., Welsh, J. A., Metcalf, R. A., Stampfer, M. R., Fusenig, N., and Rogan, E. M. (1993). p53 mutations in human immortalized epithelial cell lines. Carcinogenesis 14, 833-839.

Los, M., Mozoluk, M., Ferrari, D., Stepczynska, A., Stroh, C., Renz, A., Herceg, Z., Wang, Z. Q., and Schulze-Osthoff, K. (2002). Activation and caspase-mediated inhibition of PARP: a molecular switch between fibroblast necrosis and apoptosis in death receptor signaling. Molecular biology of the cell 13, 978-988. 
635

636

637

638

639

640

641

642

643

644

645

646

647

648

649

650

651

652

653

654

655

656

657

658

659

660

661

662

663

664

665

666

667

668

669

670

671

672

673

Ludlum, D. B., Austin-Ritchie, P., Hagopian, M., Niu, T. Q., and Yu, D. (1994). Detection of sulfur mustard-induced DNA modifications. Chemico-biological interactions 91, 39-49.

Ludlum, D. B., Kent, S., and Mehta, J. R. (1986). Formation of O6-ethylthioethylguanine in DNA by reaction with the sulfur mustard, chloroethyl sulfide, and its apparent lack of repair by 06-alkylguanine-DNA alkyltransferase. Carcinogenesis 7, 1203-1206.

Mah, L. J., El-Osta, A., and Karagiannis, T. C. (2010). gammaH2AX: a sensitive molecular marker of DNA damage and repair. Leukemia 24, 679-686.

Mangerich, A., Debiak, M., Birtel, M., Ponath, V., Balszuweit, F., Lex, K., Martello, R., Burckhardt-Boer, W., Strobelt, R., Siegert, M., Thiermann, H., Steinritz, D., Schmidt, A., and Burkle, A. (2015). Sulfur and nitrogen mustards induce characteristic poly(ADP-ribosyl)ation responses in HaCaT keratinocytes with distinctive cellular consequences. Toxicology letters.

Marchenko, N. D., Zaika, A., and Moll, U. M. (2000). Death signal-induced localization of p53 protein to mitochondria. A potential role in apoptotic signaling. The Journal of biological chemistry 275, 16202-16212.

Meier, H. L., Gross, C. L., and Papirmeister, B. (1987). 2,2'-Dichlorodiethyl sulfide (sulfur mustard) decreases NAD+ levels in human leukocytes. Toxicology letters 39, 109-122.

Meijer, A. J., and Codogno, P. (2006). Signalling and autophagy regulation in health, aging and disease. Molecular aspects of medicine 27, 411-425.

Mol, M. A., van de Ruit, A. M., and Kluivers, A. W. (1989). NAD+ levels and glucose uptake of cultured human epidermal cells exposed to sulfur mustard. Toxicology and applied pharmacology 98, 159-165.

Mol, M. A., van den Berg, R. M., and Benschop, H. P. (2009). Involvement of caspases and transmembrane metalloproteases in sulphur mustard-induced microvesication in adult human skin in organ culture: directions for therapy. Toxicology 258, 39-46.

Munoz-Gamez, J. A., Rodriguez-Vargas, J. M., Quiles-Perez, R., Aguilar-Quesada, R., Martin-Oliva, D., de Murcia, G., Menissier de Murcia, J., Almendros, A., Ruiz de Almodovar, M., and Oliver, F. J. (2009). PARP-1 is involved in autophagy induced by DNA damage. Autophagy 5, 61-74.

Naraghi, Z. S., Mansouri, P., and Mortazavi, M. (2005). A clinicopathological study on acute cutaneous lesions induced by sulfur mustard gas (yperite). European journal of dermatology : EJD 15, 140-145.

Navarro-Yepes, J., Burns, M., Anandhan, A., Khalimonchuk, O., del Razo, L. M., Quintanilla-Vega, B., Pappa, A., Panayiotidis, M. I., and Franco, R. (2014). Oxidative stress, redox signaling, and autophagy: cell death versus survival. Antioxidants \& redox signaling 21, 66-85.

Papirmeister, B., Gross, C. L., Meier, H. L., Petrali, J. P., and Johnson, J. B. (1985). Molecular basis for mustardinduced vesication. Fundamental and applied toxicology : official journal of the Society of Toxicology 5, S134-149.

Rosenthal, D. S., Simbulan-Rosenthal, C. M., Iyer, S., Spoonde, A., Smith, W., Ray, R., and Smulson, M. E. (1998). Sulfur mustard induces markers of terminal differentiation and apoptosis in keratinocytes via a Ca2+-calmodulin and caspase-dependent pathway. The Journal of investigative dermatology 111, 64-71.

Rosenthal, D. S., Simbulan-Rosenthal, C. M., Liu, W. F., Velena, A., Anderson, D., Benton, B., Wang, Z. Q., Smith, W., Ray, R., and Smulson, M. E. (2001). PARP determines the mode of cell death in skin fibroblasts, but not keratinocytes, exposed to sulfur mustard. The Journal of investigative dermatology 117, 1566-1573.

Smith, K. J., Hurst, C. G., Moeller, R. B., Skelton, H. G., and Sidell, F. R. (1995). Sulfur mustard: its continuing 
674 threat as a chemical warfare agent, the cutaneous lesions induced, progress in understanding its mechanism of

675 action, its long-term health effects, and new developments for protection and therapy. Journal of the American 676 Academy of Dermatology 32, 765-776.

677 Smith, W. J., Gross, C. L., Chan, P., and Meier, H. L. (1990). The use of human epidermal keratinocytes in culture 678 as a model for studying the biochemical mechanisms of sulfur mustard toxicity. Cell biology and toxicology 6, 285679291.

680 Sodhi, R. K., Singh, N., and Jaggi, A. S. (2010). Poly(ADP-ribose) polymerase-1 (PARP-1) and its therapeutic 681 implications. Vascular pharmacology 53, 77-87.

682 Steinritz, D., Emmler, J., Hintz, M., Worek, F., Kreppel, H., Szinicz, L., and Kehe, K. (2007). Apoptosis in sulfur 683 mustard treated A549 cell cultures. Life sciences 80, 2199-2201.

684 Thiriet, C., and Hayes, J. J. (2005). Chromatin in need of a fix: phosphorylation of H2AX connects chromatin to 685 DNA repair. Molecular cell 18, 617-622.

Thomas, H. D., Calabrese, C. R., Batey, M. A., Canan, S., Hostomsky, Z., Kyle, S., Maegley, K. A., Newell, D. R., Skalitzky, D., Wang, L. Z., Webber, S. E., and Curtin, N. J. (2007). Preclinical selection of a novel poly(ADP-ribose) polymerase inhibitor for clinical trial. Molecular cancer therapeutics 6, 945-956.

Tian-Xiang, L., Wang, L. X., Wang, X. K., Chun, H. U., and Zhou, X. B. (2013). Improved synthesis of PARP antagonist veliparib. Chinese Journal of Medicinal Chemistry.

Virag, L., Robaszkiewicz, A., Rodriguez-Vargas, J. M., and Oliver, F. J. (2013). Poly(ADP-ribose) signaling in cell death. Molecular aspects of medicine 34, 1153-1167.

Wang, Y., Dawson, V. L., and Dawson, T. M. (2009). Poly(ADP-ribose) signals to mitochondrial AlF: a key event in parthanatos. Experimental neurology 218, 193-202.

Wolf, M., Siegert, M., Rothmiller, S., Scheithauer, N., Strobelt, R., Steinritz, D., Worek, F., Thiermann, H., and Schmidt, A. (2015). Characterization of sulfur mustard resistant keratinocyte cell line HaCaT/SM. Toxicology letters.

Xiong, T., Wei, H., Chen, X., and Xiao, H. (2015). PJ34, a poly(ADP-ribose) polymerase (PARP) inhibitor, reverses melphalan-resistance and inhibits repair of DNA double-strand breaks by targeting the FA/BRCA pathway in multidrug resistant multiple myeloma cell line RPMI8226/R. International journal of oncology 46, $223-232$.

Yourick, J. J., Clark, C. R., and Mitcheltree, L. W. (1991). Niacinamide pretreatment reduces microvesicle formation in hairless guinea pigs cutaneously exposed to sulfur mustard. Fundamental and applied toxicology : official journal of the Society of Toxicology 17, 533-542.

703

Yu, S. W., Wang, H., Poitras, M. F., Coombs, C., Bowers, W. J., Federoff, H. J., Poirier, G. G., Dawson, T. M., and Dawson, V. L. (2002). Mediation of poly(ADP-ribose) polymerase-1-dependent cell death by apoptosis-inducing factor. Science (New York, NY) 297, 259-263.

706

Yue, L., Wei, Y., Chen, J., Shi, H., Liu, Q., Zhang, Y., He, J., Guo, L., Zhang, T., Xie, J., and Peng, S. (2014). Abundance of four sulfur mustard-DNA adducts ex vivo and in vivo revealed by simultaneous quantification in research in toxicology $27,490-500$. 


\section{1}

Effect of PARP-1 inhibitor on pADPr content (which represents PARP-1 activity) in SMtreated $\mathrm{HaCaT}$ cell.

Cultured HaCaT cells were treated with various concentrations of SM for $6 \mathrm{~h}$. The level of pADPr protein was determined by immunofluorescence ( $A$ and $B$ ), western blotting ( $C$ and $D)$ and Acumen (E), respectively. (A and B) The scale shown in the upper left panel (bar=20um) was the same for all panels. ( $C$ and $D$ ) The results of the western blots were normalized to the levels of GAPDH and then presented as the fold of the control levels. (E) The results of the Acumen analysis were normalized to the nuclear total fluorescence intensity. ${ }^{*} P<0.01$,

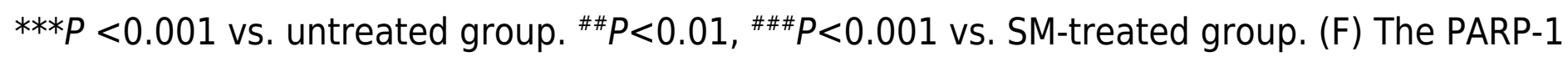
inhibitory effect of ABT-888 was also confirmed at enzyme level (Each data point represents three data points). 
A

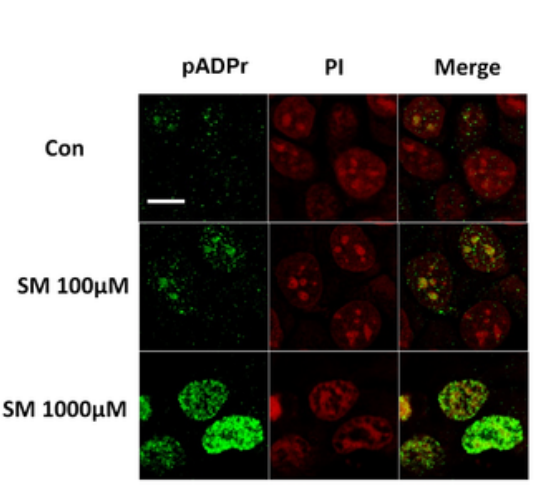

C

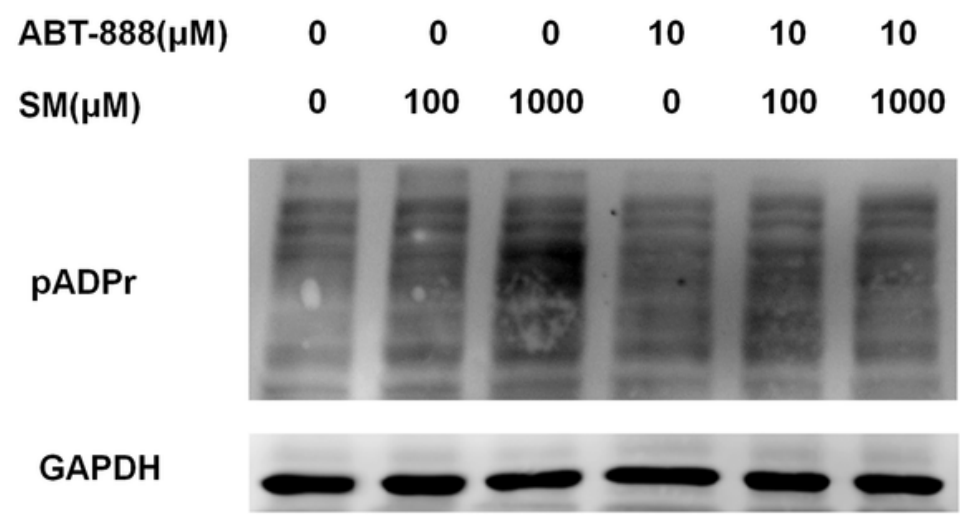

$\mathbf{E}$
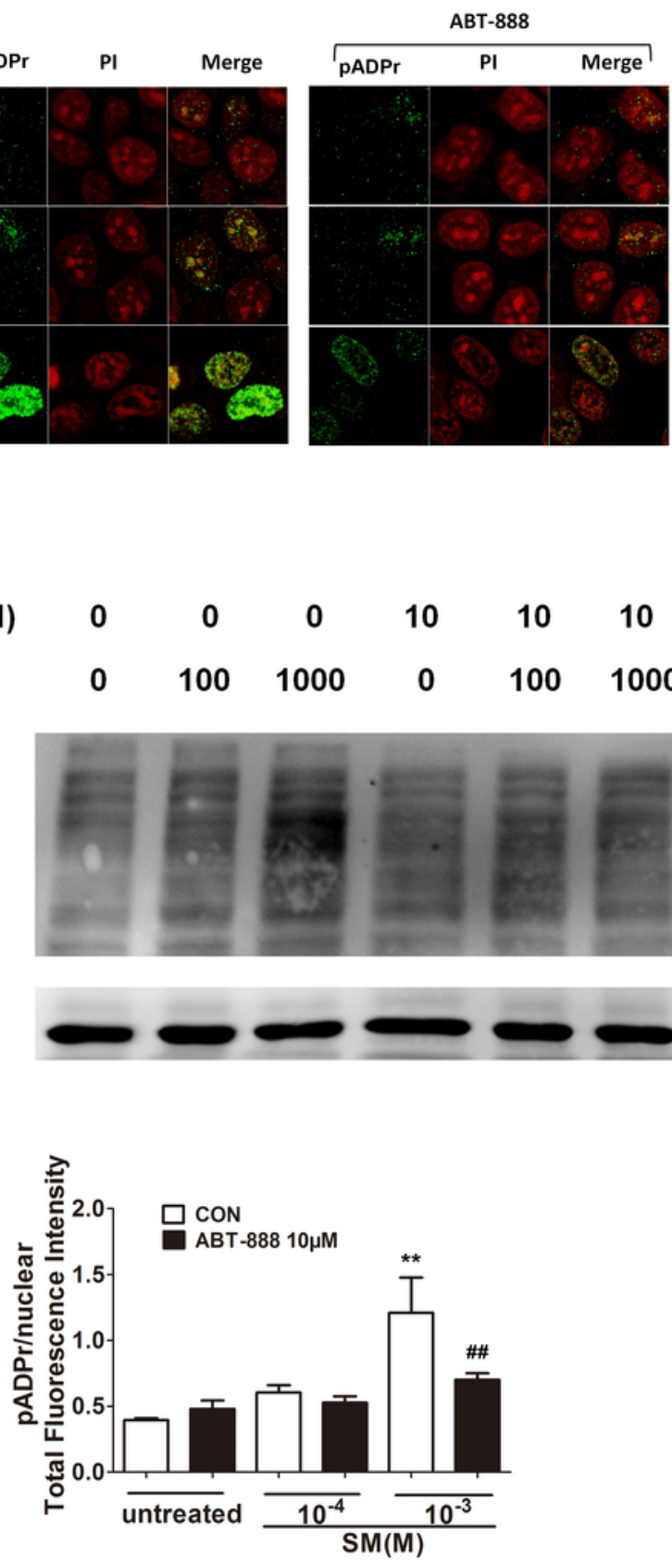

B

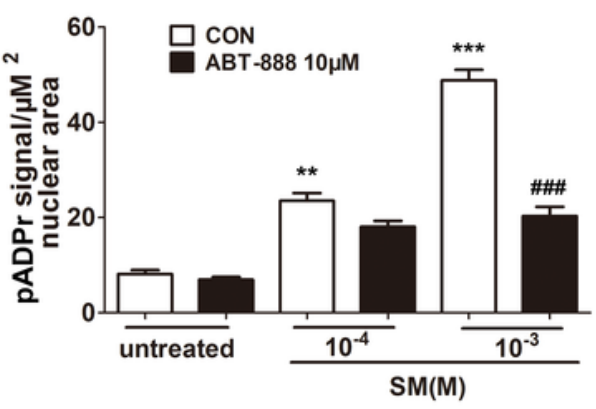

D

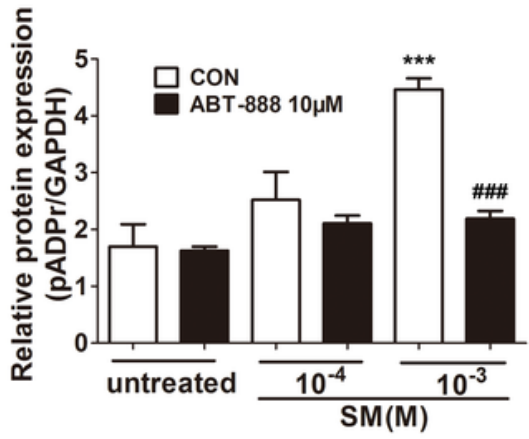

$\mathbf{F}$

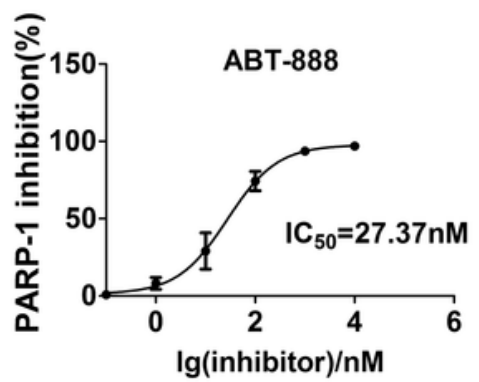


2

Effect of PARP inhibitor on cell survival in SM-treated HaCaT cell.

Cell viability was quantified using the Cell Counting Kit-8 6 h (D) and 24h (E) after SM

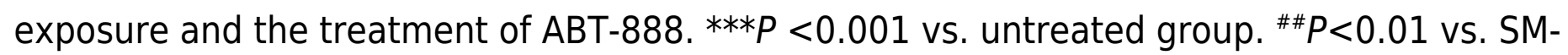
treated group. All the data were presented as the means \pm SEM $(n=6)$. 


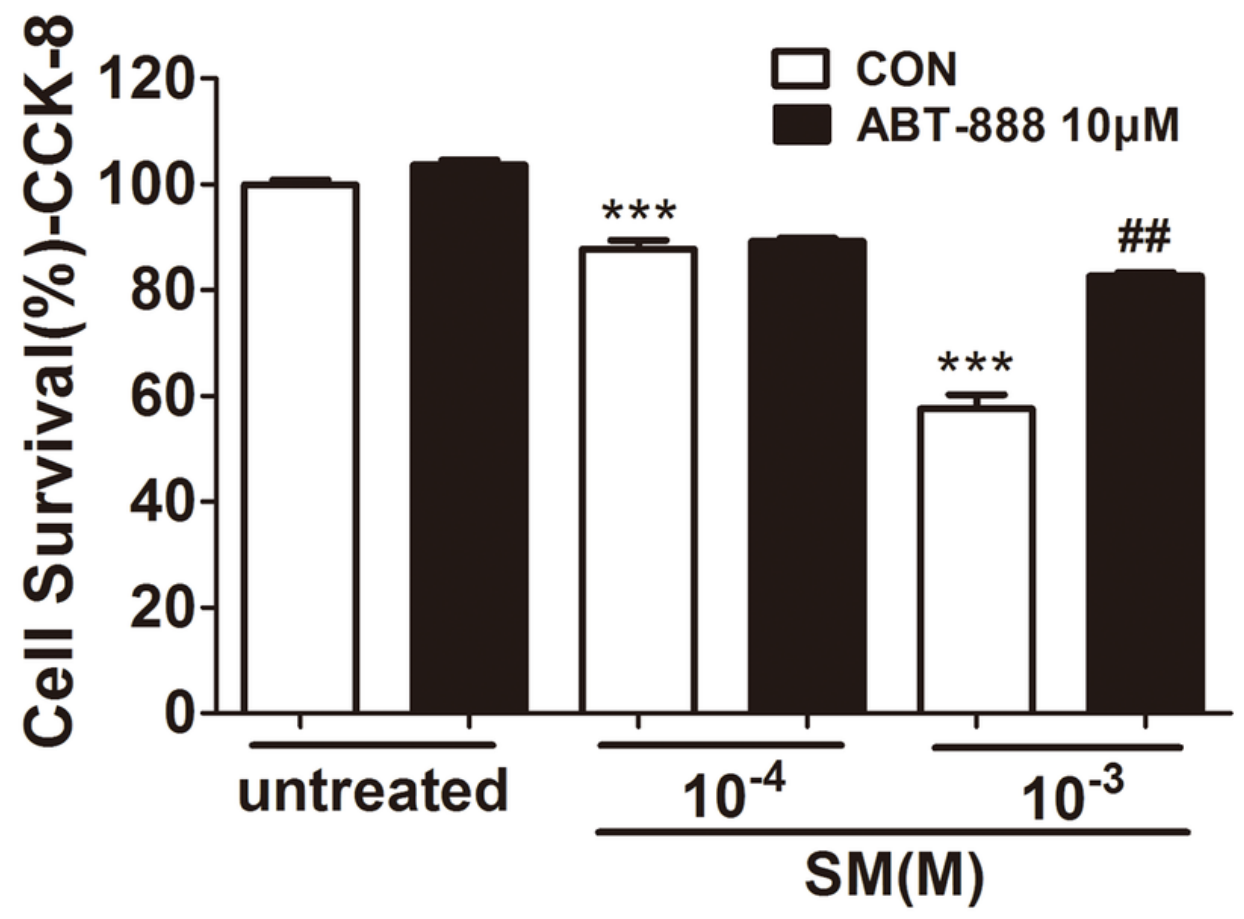

B

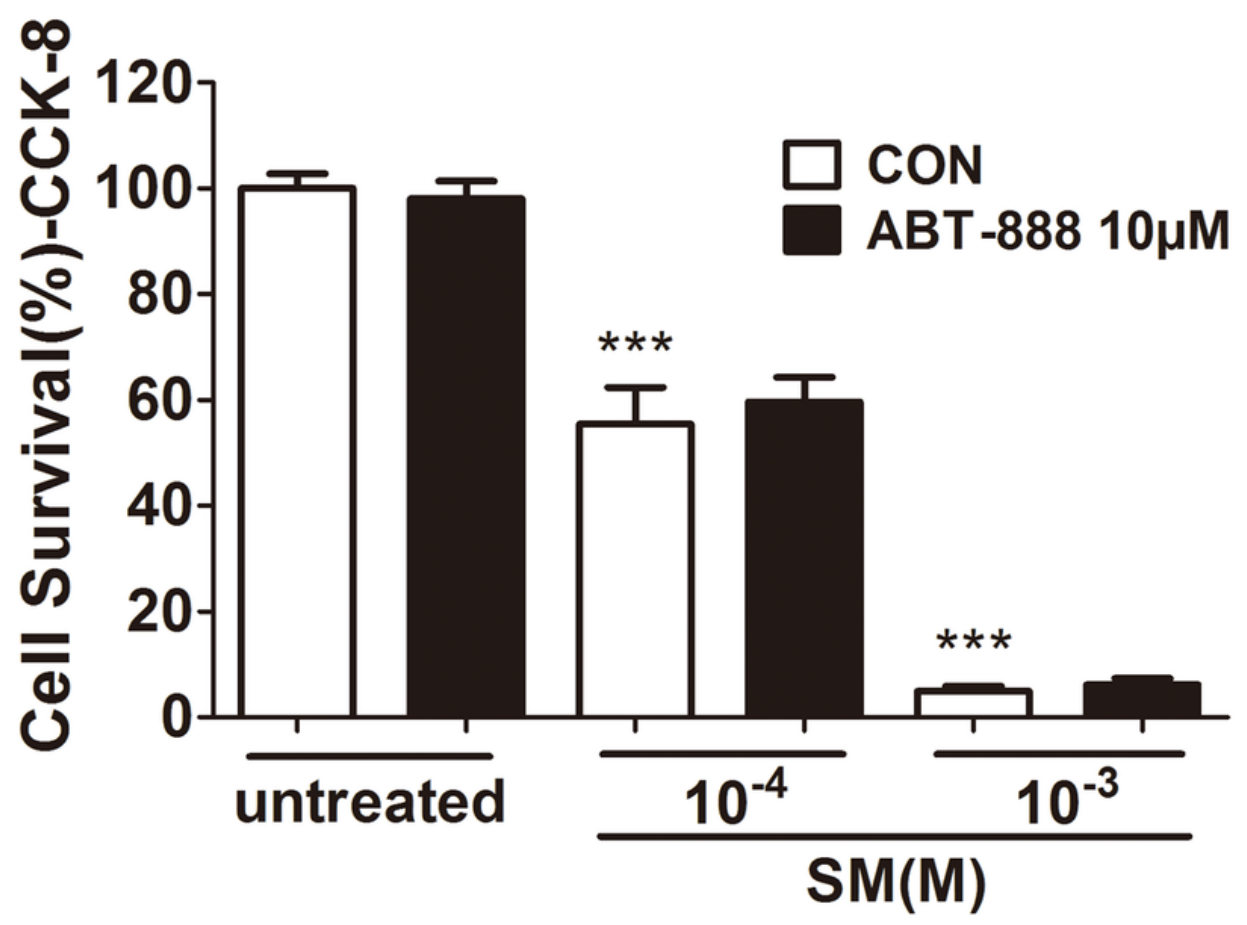




\section{3}

Effect of PARP-1 inhibitor on relative ear weight and histopathological change in SMtreated mouse ear vesicant model.

(A) Hematoxylin and eosin stains of the mouse ear skin showed that the PARP inhibitor ABT888 did not have a protective effect against pathological damage in mice exposed to $0.16 \mathrm{mg}$ SM/ear, but ABT-888 produced reductions in pathological damage in mice exposed to $0.64 \mathrm{mg}$ SM/ear. (a) The medial surface of a normal ear from the control group. (b) The medial surface of an ear from the $0.16 \mathrm{mg}$ SM/ear exposure group, showing epidermal necrosis (pyknotic nuclei, arrowhead). (c) The medial surface of an ear from the $0.16 \mathrm{mg}$ SM/ear exposure + ABT-888 group. ABT-888 showed no protective effect. (d) The medial surface of an ear from the $0.64 \mathrm{mg} \mathrm{SM} /$ ear exposure group. Epidermal necrosis (arrowhead) was progressively more severe. (e) The medial surface of an ear from the $0.64 \mathrm{mg}$ SM/ear exposure + ABT-888 group. ABT-888 could reduce reticular degenerative changes in the dermis, hypereosinophilic cytoplasms of the epidermis necrosis (arrowhead). The scale shown in the lower right panel (bar $=20 \mu \mathrm{m}$ ) is the same for all panels. (B and C) ABT-888 significantly reduced edema (REW, approximately $26 \%$ ) of the ear and epidermal necrosis (EN score, approximately $40 \%$ ) in MEVM in the group exposed to $0.64 \mathrm{mg} \mathrm{SM} / \mathrm{ear}$, but showed no protective effect in the group exposed to $0.16 \mathrm{mg}$ SM/ear. ABT-888 was administered (i.p.) 30 min before the SM exposure. $* P<0.05$ vs. $0.64 \mathrm{mg}$ SM/ear. All the data are presented as the means \pm SEM $(n=5 \sim 7)$. 
A

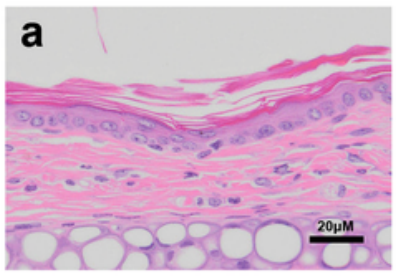

b

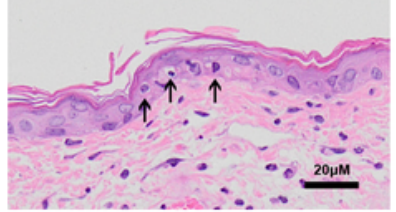

C

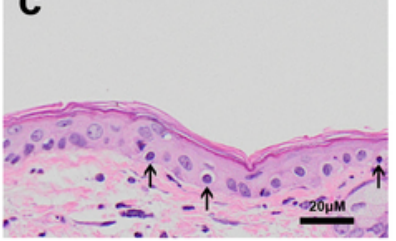

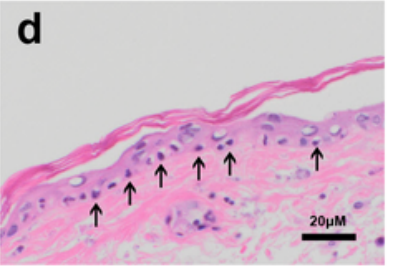

e

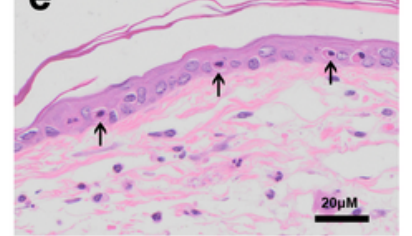

B

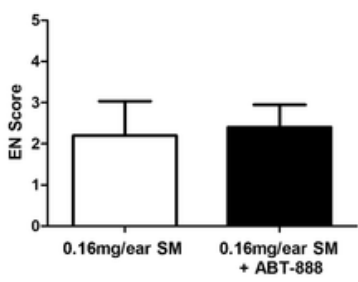

C

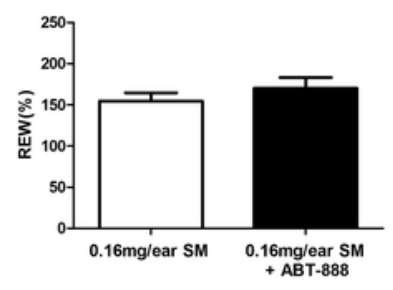

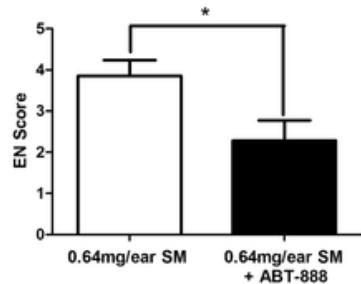

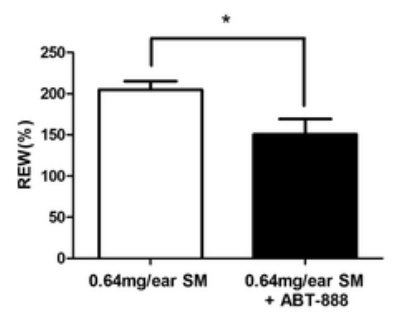


4

The effects of the PARP inhibitor on NAD+/ATP content in SM-treated HaCaT cell.

Intracellular NAD+ levels were measured $6 \mathrm{~h}(\mathrm{~A})$ and $24 \mathrm{~h}(\mathrm{~B})$ after SM exposure and the treatment of ABT-888. Intracellular ATP levels were measured $6 \mathrm{~h}(\mathrm{C})$ and $24 \mathrm{~h}(\mathrm{D})$ after SM exposure and the treatment of ABT-888. The values are presented as the means $\pm S E M, n=3$ or 6. ${ }^{*} P<0.05,{ }^{* *} P<0.01,{ }^{* * * P} P<0.001$ vs. untreated group. ${ }^{\#} P<0.05,{ }^{\# \#} P<0.001$ vs. SMtreated group.
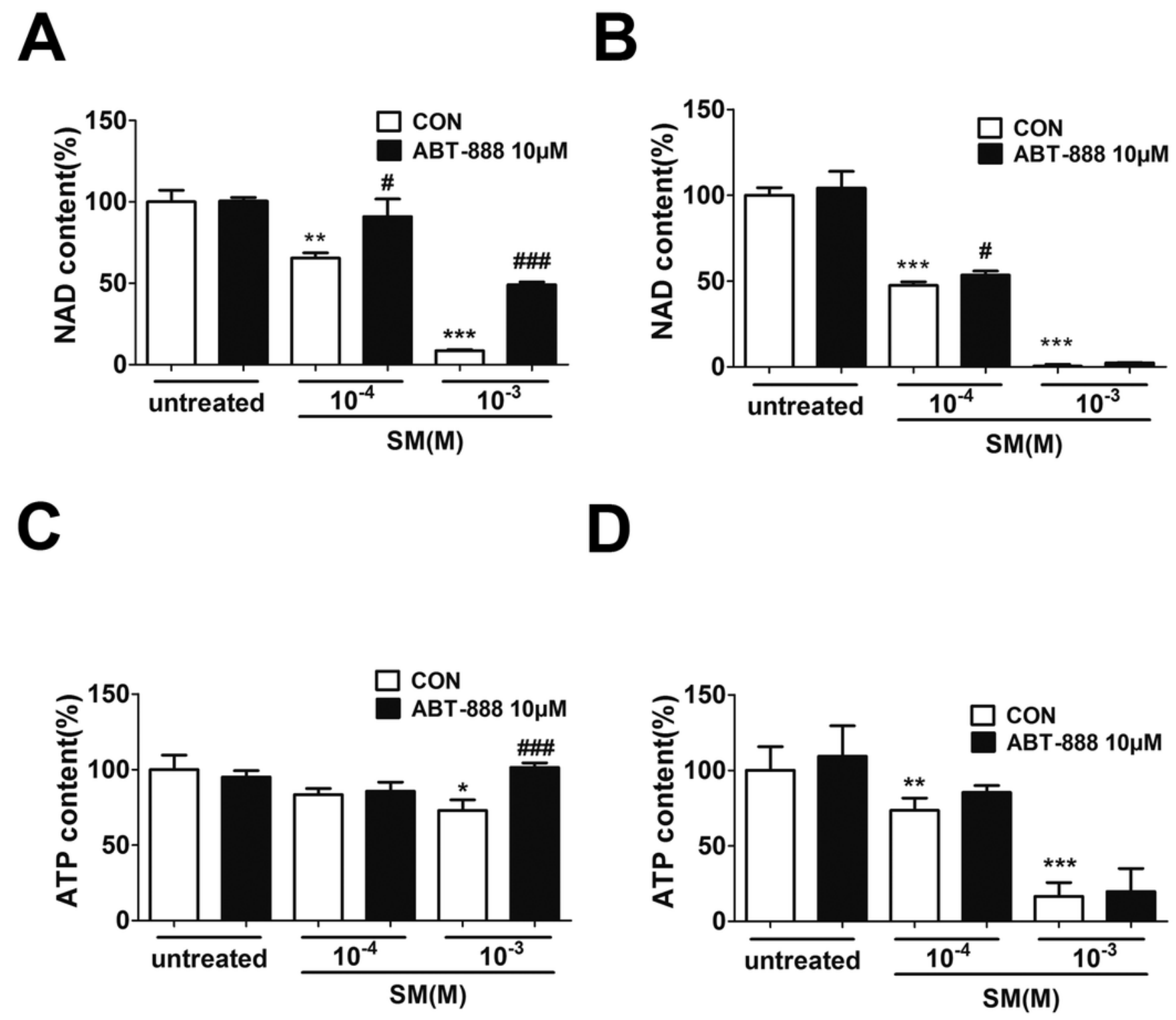


\section{5}

The effects of the PARP inhibitor ABT-888 on apoptosis/necrosis in SM-treated HaCaT cell.

Caspase 3/7 activity was measured $6 \mathrm{~h}(\mathrm{~A})$ and $24 \mathrm{~h}(\mathrm{~B})$ after SM exposure and the treatment of ABT-888. Total cell lysates were prepared and analyzed for protein expression by western blotting using anti-PARP-1 and cleavage of PARP-1 antibody $6 \mathrm{~h}$ (C) and 24h (D) after SM exposure and the treatment of ABT-888. $\beta$-Actin was used as a control to ensure equal protein loading. Apoptosis and necrosis were analyzed by flow cytometry $6 \mathrm{~h}(\mathrm{E})$ and $24 \mathrm{~h}(\mathrm{~F})$ after SM exposure and the treatment of ABT-888. The frames were divided into four quadrants: Annexin V-/PI- normal cells are in quadrant I; Annexin V+/PI- apoptotic cells are in quadrant II; $\mathrm{PI}+$ necrotic cells are in quadrant III/IV. The values are presented as the means \pm

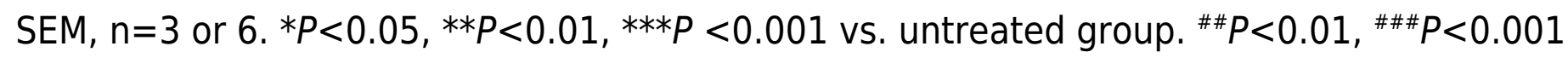
vs. SM-treated group. 
A

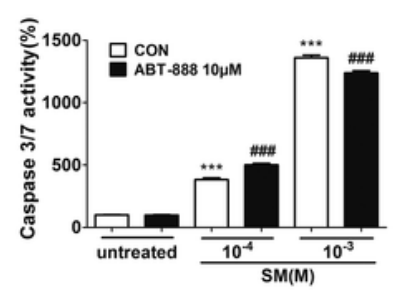

B

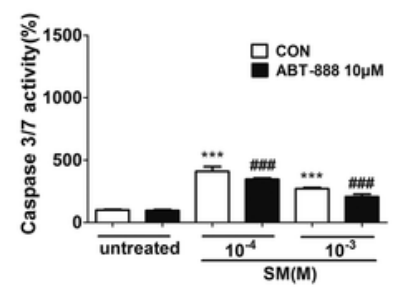

C

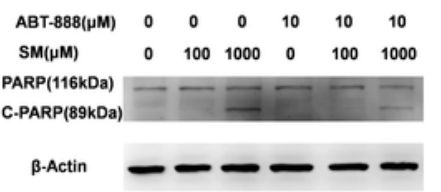

$\beta$-Actin

E
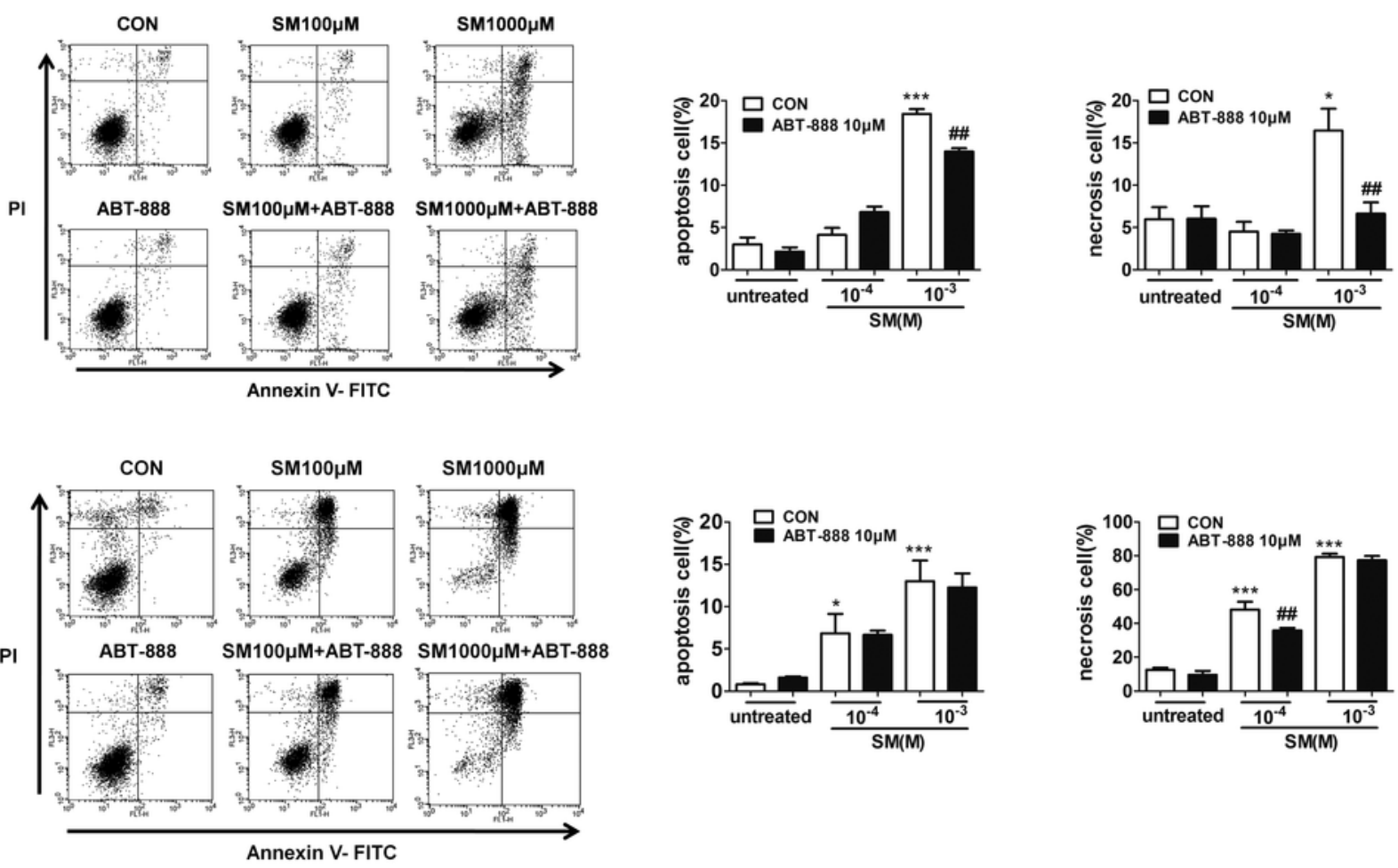

D

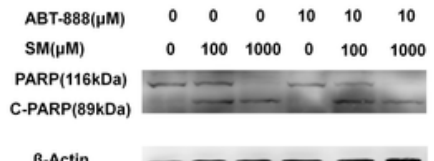

(actin

$\mathbf{F}$

Annexin V- FITC

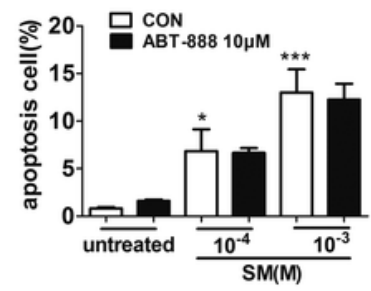


6

Knockdown of PARP-1 suppressed the toxicity of SM at the level of cell viability.

To evaluate whether PARP-1 was involved in the toxicity of SM, LV-ShPARP-1 and LV-shCon were transfected into HaCaT cells; then, stable transfectants were selected. The efficacy for PARP-1 knockdown was determined by RT-PCR (A) and western blotting (B). The control and PARP-1 knockdown HaCaT cells were treated with 0, 100, or $1000 \mu \mathrm{M}$ SM. Subsequently, the cell viability was measured $6 \mathrm{~h}(\mathrm{C})$ and $24 \mathrm{~h}(\mathrm{D})$ after exposure to SM. The results are presented as the means \pm SEM determined from three independent experiments. ${ }^{* * *} P$ $<0.001$ vs. untreated group. ${ }^{\# P<0.05, ~}{ }^{\# \#} P<0.001$ vs. SM-treated group.

A

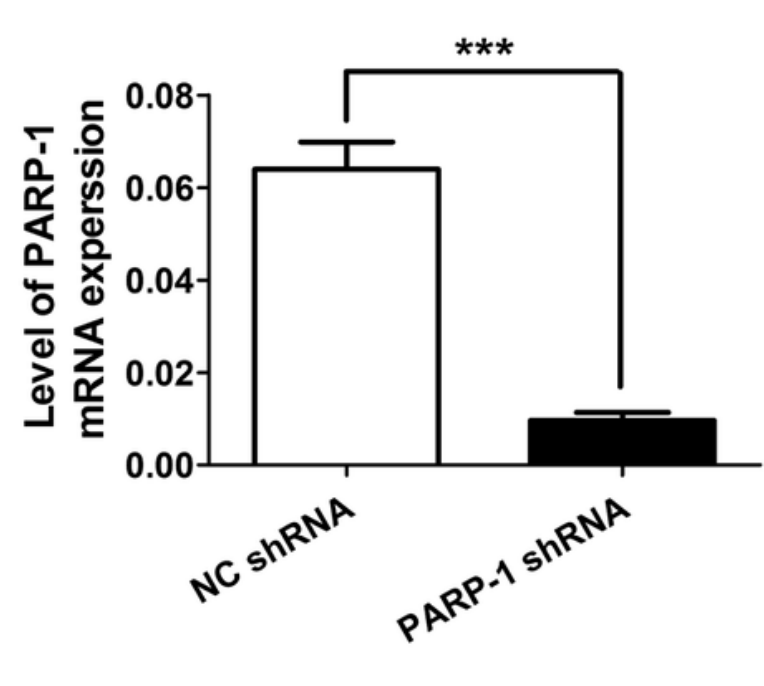

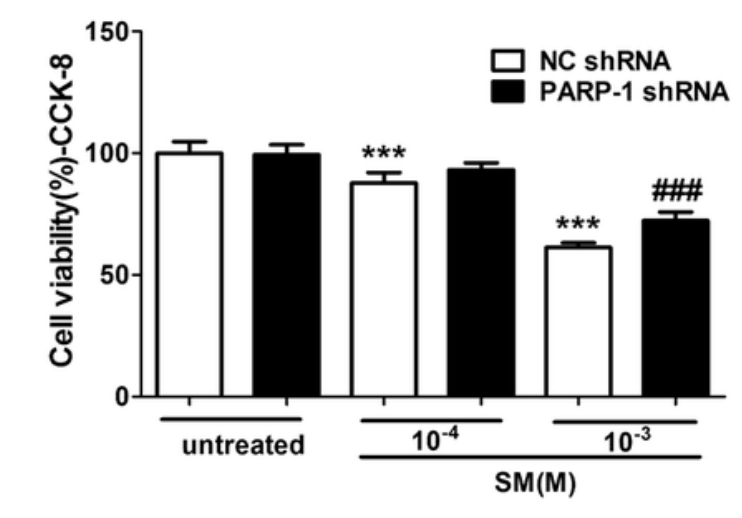

C
B

PARP-1

ACTIN

NC PARP-1

ShRNA ShRNA

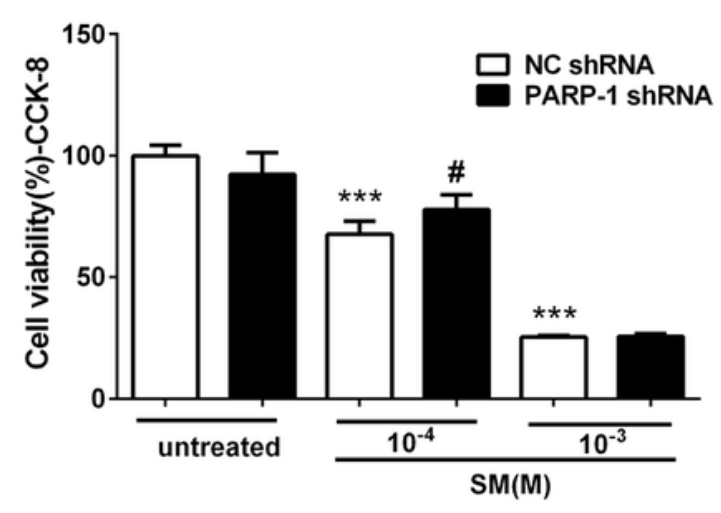




\section{7}

SM-induced activation of apoptosis checkpoint signals was suppressed by PARP-1 knockdown in HaCaT cells. ected.

PARP-1-knockdown and control HaCaT cells were treated with $100 \mu \mathrm{M}$ or $1000 \mu \mathrm{M} \mathrm{SM}$. At $6 \mathrm{~h}$ and $24 \mathrm{~h}$ after exposure to SM, the cells were harvested for the detection of the apoptosis checkpoint signals. The protein levels of phospho-JNK (Thr183/Tyr185) $6 \mathrm{~h} \mathrm{(A)} \mathrm{and} 24 \mathrm{~h}$ (B) after exposure to SM, phospho-P53 (ser46) $6 \mathrm{~h}$ (C) and $24 \mathrm{~h}$ (D) after exposure to SM, active Caspase 9 (Asp315) $6 \mathrm{~h}$ (E) and $24 \mathrm{~h}$ (F) after exposure to SM, active Caspase 8 (Asp384) $6 \mathrm{~h}$ (G) and $24 \mathrm{~h} \mathrm{(H)} \mathrm{after} \mathrm{exposure} \mathrm{to} \mathrm{SM,} \mathrm{and} \mathrm{c-PARP} \mathrm{(p89)} 6 \mathrm{~h}(\mathrm{~K})$ and $24 \mathrm{~h} \mathrm{(L)}$ after exposure to SM were determined using Luminex assays. The caspase $3 / 7$ activity $6 \mathrm{~h}$ (I) and $24 \mathrm{~h}$ (J) after exposure to SM was measured using the Caspase-Glo 3/7 assay kit. The results are presented as the means $\pm S E M$, as determined from three independent experiments.

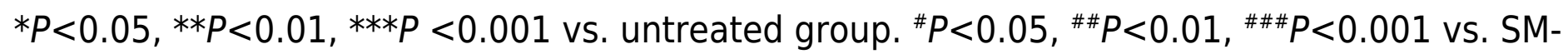
treated group. 

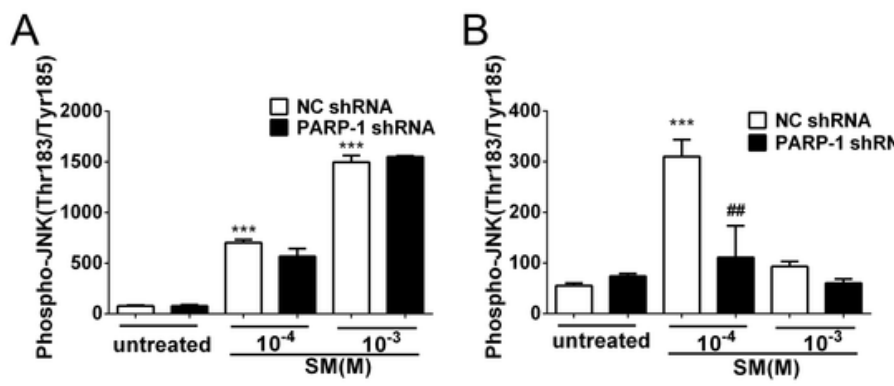

C

D

$\mathrm{E}$

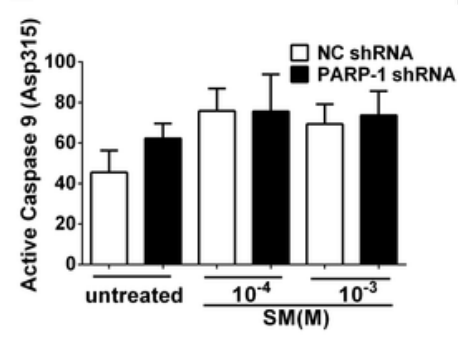

I

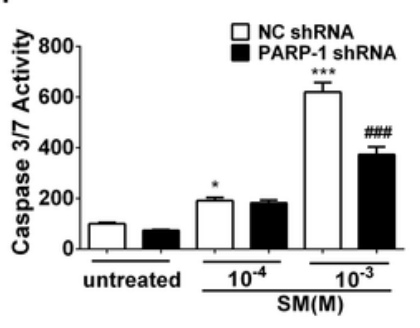

$\mathrm{F}$

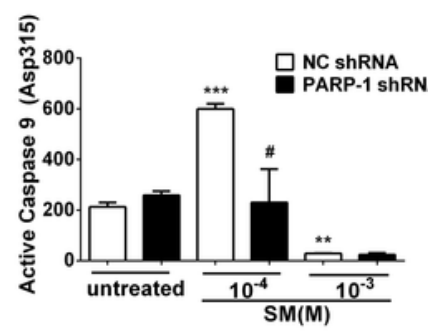

$\mathrm{J}$

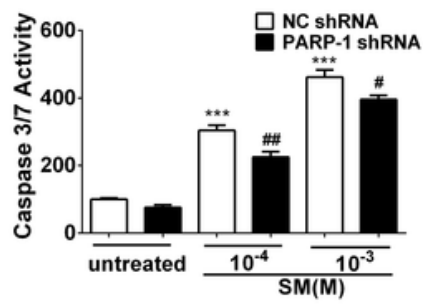

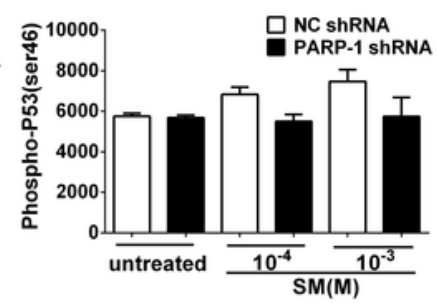

G

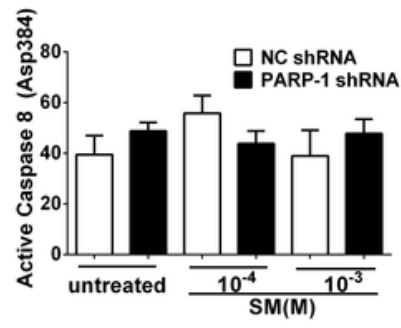

$\mathrm{K}$

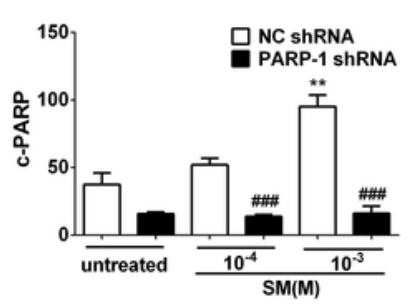

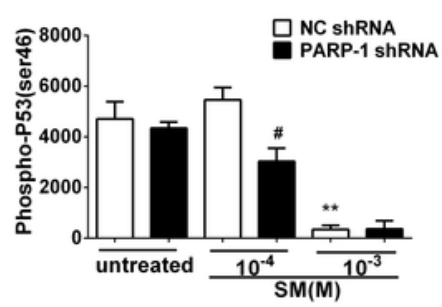

$\mathrm{H}$

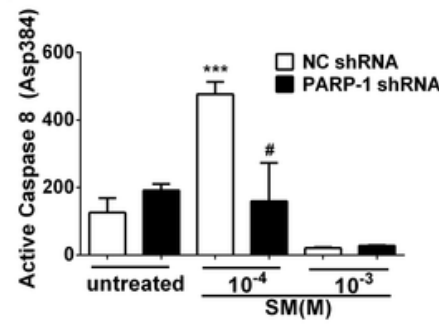

L

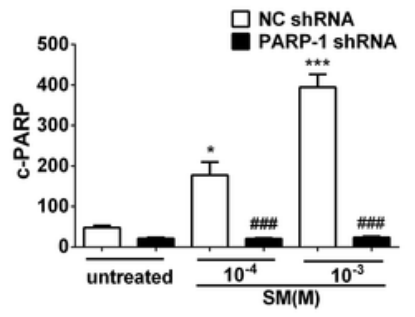


8

SM-induced suppression of Akt/mTOR signaling could be reversed by silencing PARP-1.

PARP-1-knockdown and control HaCaT cells were treated with $100 \mu \mathrm{M}$ or $1000 \mu \mathrm{M}$ SM. At $6 \mathrm{~h}$ and $24 \mathrm{~h}$ after exposure to SM, the cells were harvested for the detection of Phospho-AKT (Thr308) (A, B) and Phospho-mTOR (Ser2448) (C, D). The results are presented as the means \pm SEM, as determined from three independent experiments. ${ }^{*} P<0.05$, ${ }^{*} P<<0.01$, vs.

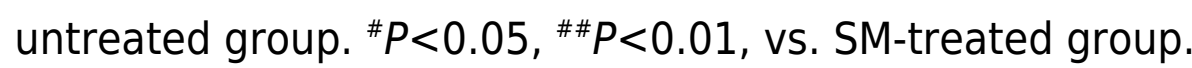

A

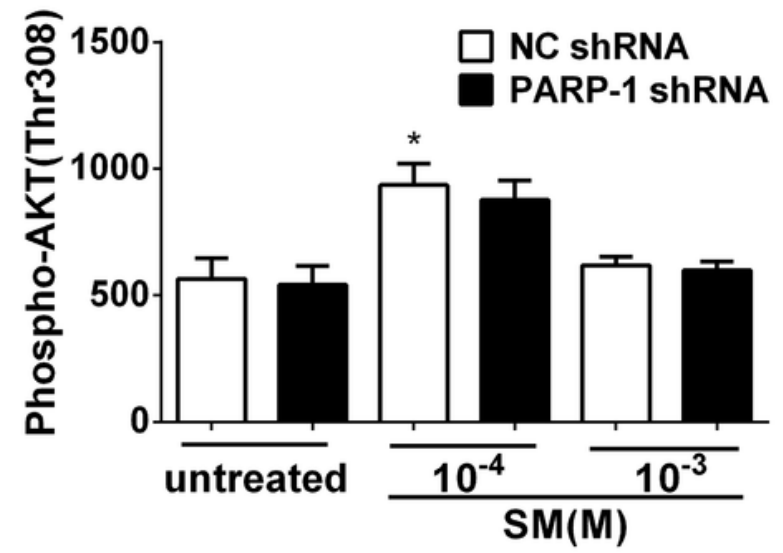

C

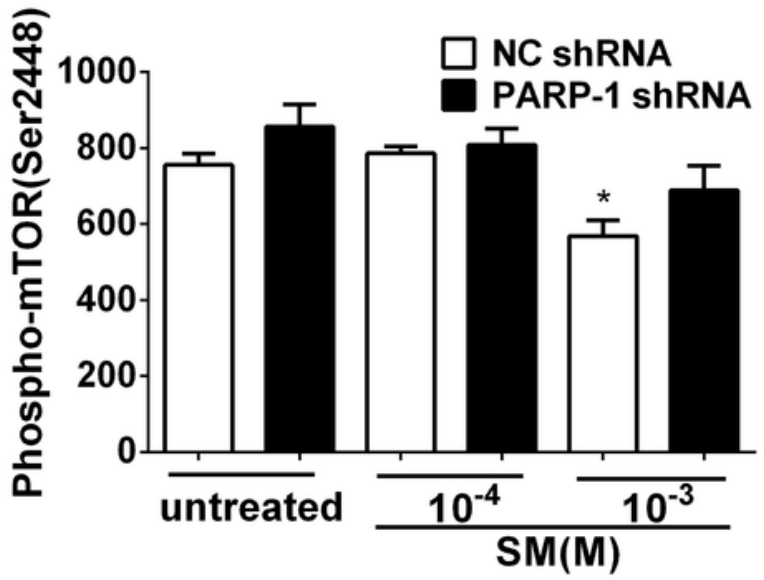

B
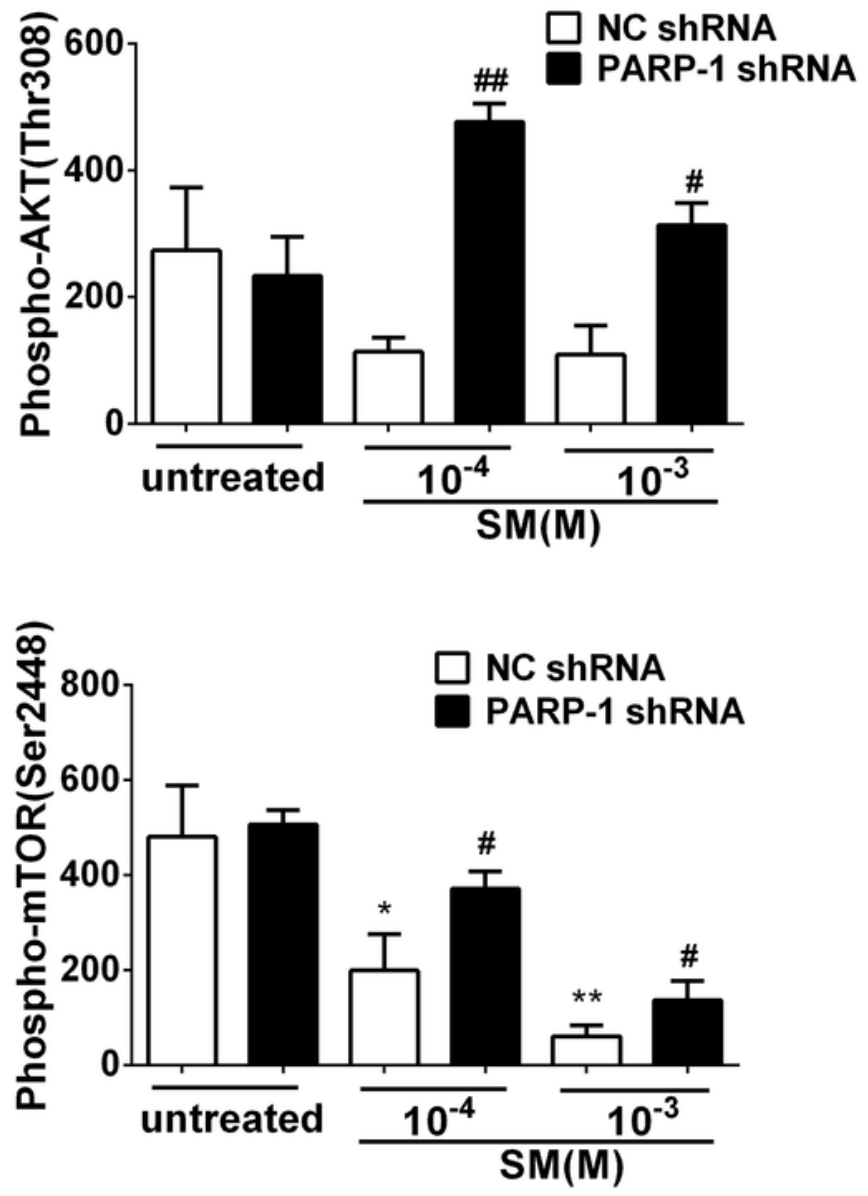
9

SM treatment caused a significant increase in the expression of $\mathrm{Y}-\mathrm{H} 2 \mathrm{AX}$, which was further increased by ABT-888.

(A) $6 \mathrm{~h}$ post SM exposure, (B) $24 \mathrm{~h}$ post SM exposure. Representative examples of FACS data are displayed. ${ }^{* * *} P<0.001$ vs. untreated group. ${ }^{\# \#} P<0.001$ vs. SM-treated group. The values are presented as the means $\pm S E M, n=6$.

A
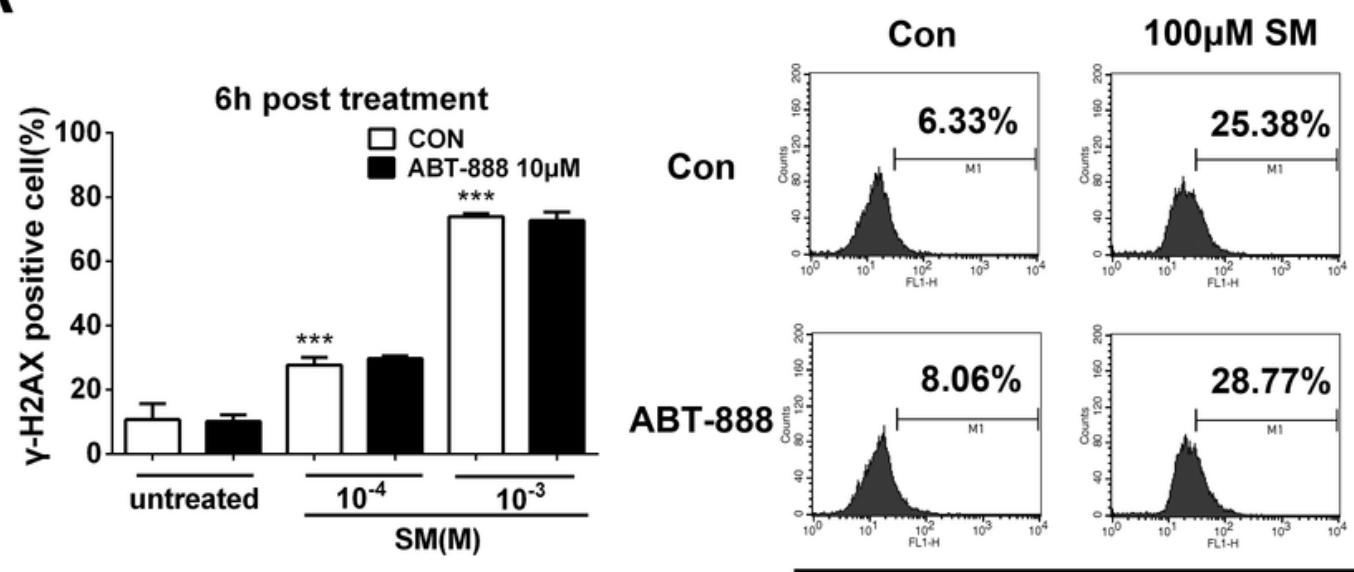

$1000 \mu \mathrm{M}$ SM
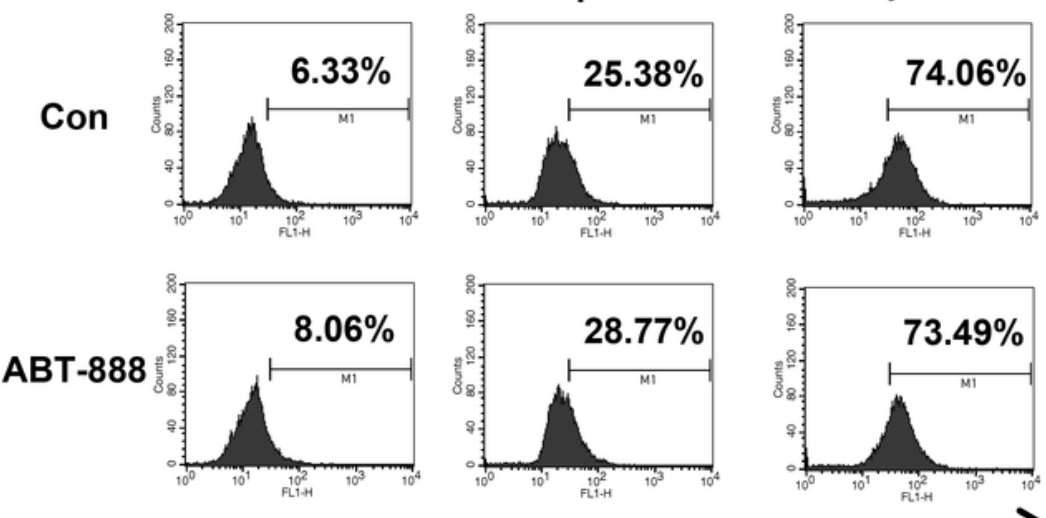

Y-H2AX

$\mathrm{B}$

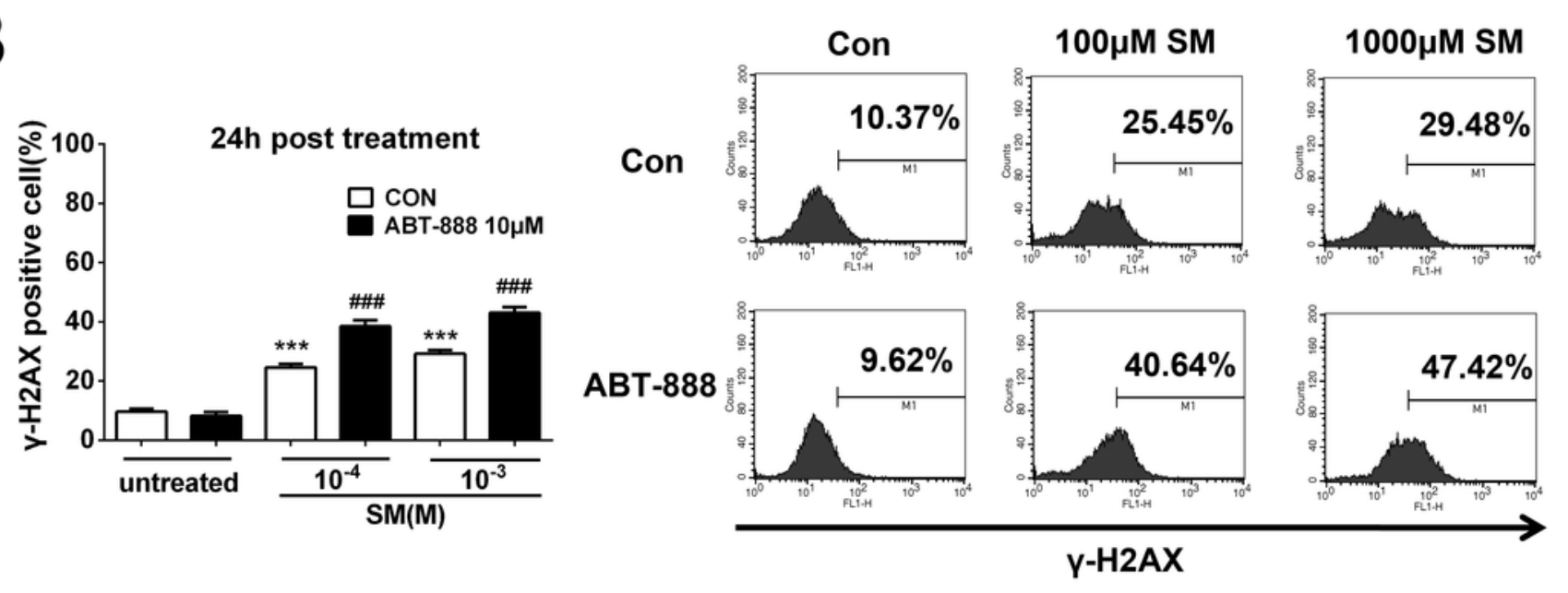


10

Schematic of the role of PARP-1 in sulfur mustard injury.

For details see text.

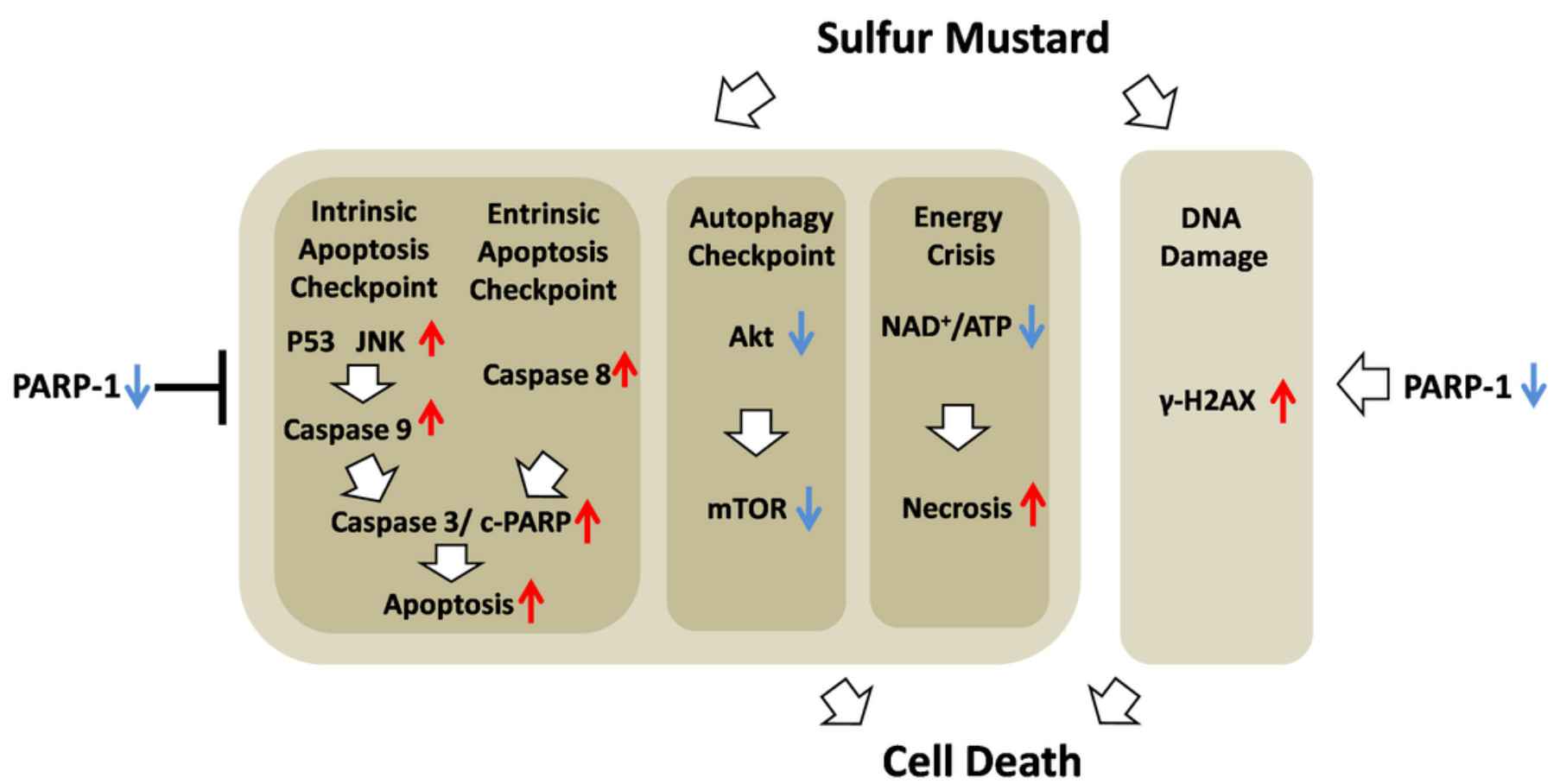

